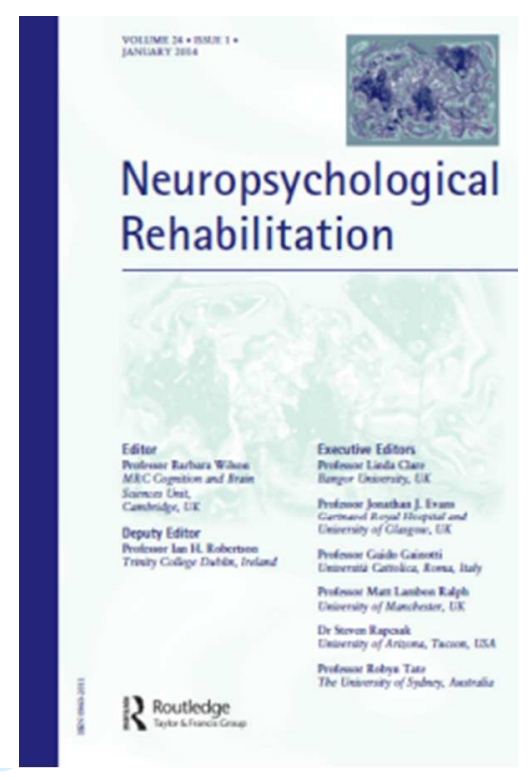

\title{
Social Anxiety Following Traumatic Brain Injury: An Exploration of Associated Factors
}

\begin{tabular}{|r|l|}
\hline Journal: & Neuropsychological Rehabilitation \\
\hline Manuscript ID & NRH-OA 132.15.R1 \\
\hline Manuscript Type: & Original Articles \\
\hline Date Submitted by the Author: & 19-Mar-2016 \\
\hline Complete List of Authors: & $\begin{array}{l}\text { Curvis, William; Doctorate in Clinical Psychology, Division of Health } \\
\text { Research } \\
\text { Simpson, Jane; Doctorate in Clinical Psychology, Division of Health } \\
\text { Research } \\
\text { Hampson, Natalie; Salford Royal NHS Foundation Trust }\end{array}$ \\
\hline Keywords: & traumatic brain injury, social anxiety, stigma, psychological \\
\hline &
\end{tabular}

SCHOLARONE ${ }^{\text {Ix }}$

Manuscripts 
Dr William Curvis, Lancaster University, Lancaster, UK.

Dr Jane Simpson, Lancaster University, Lancaster, UK.

Dr Natalie Hampson, Salford Royal NHS Foundation Trust, Salford, UK.

Abstract word count: 185

Word count (excluding abstract, references, appendices \& tables): 6940

Correspondence should be addressed to:

Dr William Curvis, Doctorate in Clinical Psychology, Division of Health Research, Floor C, Furness College, Lancaster University, Lancaster L1 4YG.

E-mail: wcurvis@gmail.com 


\begin{abstract}
Social anxiety (SA) following traumatic brain injury (TBI) has the potential to affect an individual's general psychological wellbeing and social functioning, however little research has explored factors associated with its development. The present study used hierarchical multiple regression to investigate the demographic, clinical and psychological factors associated with SA following TBI. A sample of 85 people who experienced TBI were recruited through social media websites and brain injury services across the NorthWest of England. The overall combined biopsychosocial model was significant, explaining 52-54.3\% of the variance in SA (across five imputations of missing data). The addition of psychological variables (self-esteem, locus of control, self-efficacy) made a significant contribution to the overall model, accounting for an additional $12.2-13 \%$ of variance in SA above that explained by demographic and clinical variables. Perceived stigma was the only significant independent predictor of SA $(B=.274, p=.005)$. The findings suggest that psychological variables are important in the development of SA following TBI and must be considered alongside clinical factors. Furthermore, the significant role of stigma highlights the need for intervention at both an individualised and societal level.
\end{abstract}

Keywords: traumatic brain injury, social anxiety, stigma, psychological 
Social Anxiety Following Traumatic Brain Injury: An Exploration of Associated Factors

People who have experienced a traumatic brain injury (TBI) are at increased risk of developing psychological difficulties such as depression and anxiety (Scholten et al., 2016; Osborn, Mathias, \& Fairweather-Schmidt, 2014; Gould, Ponsford, Johnston and Schönberger, 2011; Whelan-Goodinson, Ponsford, Schönberger \& Johnston, 2010; Bryant et al., 2010). However, recognising psychological problems after TBI can be challenging, given the complex interactions between the neurological and emotional sequelae of TBI and the difficulties in identifying symptoms of psychological problems in the context of other factors (e.g., cognitive impairment, physical disability) associated with TBI (Kim et al., 2007; Scheutzow \& Wiercisiewski, 1999). Nonetheless, as psychological problems following TBI can be longstanding (Konrad et al., 2011) and may affect wellbeing and inhibit recovery (Osborn et al., 2014), it is imperative to improve understanding and management of these difficulties during assessment and rehabilitation (Williams, Evans \& Fleminger, 2003).

Furthermore, it is vital to understand the social context in which TBI rehabilitation occurs. Social functioning is commonly affected by TBI and this can have a significant impact on life satisfaction (Pierce \& Hanks, 2006; Truelle, Fayol, Montreuil, \& Chevignard, 2010; Jones et al., 2010). Qualitative research highlights the importance of social activity following TBI in making sense of oneself (Yeates, Gracey, \& Mcgrath, 2008), and social support is predictive of lower levels of post-traumatic stress (Jones et al., 2012). However, declines in activity, social contact, independence, functional status and employment opportunities are often reported following TBI (Antonak, Livneh, \& Antonak, 1993; Temkin, Corrigan, Dikmen, \& Machamer, 2009). Severity of injury fails to account fully for differences in psychosocial functioning (Antonak et al., 1993) and life satisfaction post-TBI (Jones et al., 2010), with the latter study finding that social support mediated the relationship between well-being and injury severity. 
Moreover, following TBI people may feel embarrassed or self-conscious in social situations given the frequency of physical consequences (e.g., physical impairment, hemiparesis, skull depressions, scarring, tremors, motor/speech problems) and often unseen cognitive problems with word finding, attention, memory, executive functioning and processing speed (Rochat, Ammann, Mayer, Annoni, Van Der Linden, 2009; Hiott \& Labbate, 2002; Moore, Terryberry-Spohr \& Hope, 2006). Therefore, social interaction can be negatively impacted following TBI if a person is less able to follow or engage in conversation (Morris et al., 2005). Consequently, problems following TBI may result in people becoming particularly anxious in social situations (Moore et al., 2006; Wright \& Telford, 1996).

However, despite the importance of social reintegration, social anxiety in people with a TBI has been the subject of very little research. Social anxiety (SA) is characterised by a marked fear of situations in which a person might face scrutiny from others and subsequent avoidance of common triggers (e.g., social interactions, meeting new people, public speaking) which can result in significant distress and impairments in functioning (National Institute for Health and Care Excellence [NICE], 2013; American Psychiatric Association [APA], 2013). While both anxiety (Rao \& Lyketsos, 2002) and declines in psychosocial functioning (Ponsford et al., 2014; Antonak et al., 1993) following TBI are well documented, the available research examining SA following TBI is limited and of poor quality. Only two studies have been identified which have assessed social anxiety in this population. A prospective cohort study of people who had experienced traumatic injuries found that $6.1 \%$ of people with mild-TBI met criteria for SA three months post-injury, rising to $9 \%$ after 12 months (Bryant et al., 2010). Conversely, Newton and Johnson (1985) found that SA was lower in participants with a TBI compared to those without. However, the TBI group comprised only eleven participants who exhibited a broad range of scores on a measure of 
SA. The authors concluded that although the mean score was lower than the control group, a high level of SA was observed in the majority of the TBI group $(n=8)$.

This lack of research interest may be a consequence of the complex interaction and overlap between psychological and neurological problems as discussed above. It may also result from the criteria within the Diagnostic and Statistical Manual of Mental Disorders, Fifth Edition (DSM-5; APA, 2013) for SA which state that, if a medical condition is present, anxiety or avoidance must be unrelated or out of proportion to it. This suggests that a diagnostic label of social anxiety disorder may not be appropriate for people experiencing anxiety in social situations after TBI. This may result in social anxiety not being considered in this population, or such difficulties being attributed to the cognitive or neurological consequences of TBI. However, this is not in keeping with recommendations for a broad and biopsychosocial approach to providing support and rehabilitation following TBI (Gracey, Evans \& Malley, 2009; Wilson \& Gracey, 2009).

No guidance is available specific to the management of SA after TBI, but empiricallybased guidance for generic SA interventions in the UK (NICE, 2013) recommends cognitive behavioural therapy (CBT) as a first-line intervention (i.e., before pharmacological interventions), underpinned by a specifically developed theoretical model (e.g., Clark \& Wells, 1995). However, a randomised controlled trial of a CBT programme for SA after acquired brain injury $(\mathrm{ABI})$ found that although $\mathrm{SA}$ did reduce, treatment effects were not statistically significant (Hodgson, McDonald, Tate, \& Gertler, 2012). However, a small sample size $(n=12)$ and variability in the ABI group (people who had experienced stroke, hypoxic brain injury and cerebral oedema were included alongside those who had experienced TBI) limits the usefulness of this study in understanding management of SA after TBI. 
Despite the lack of research or guidance around SA after TBI, a literature review exploring anxiety following mild TBI (Moore et al., 2006) highlighted the potential for SA to be a significant problem in this population. Furthermore, Soo, Tate and Rapee (2012) present a theoretical rationale for high levels of SA in children and adolescents who have experienced TBI. They draw on Kendall and Terry's (1996) model for understanding individual differences and predicting psychosocial adjustment outcomes following TBI, acknowledging a role for direct (neurological and cognitive impairment) and indirect (situational and environmental) antecedent factors, but also emphasising the importance of an individual's psychological resources such as appraisal style and coping responses. This is consistent with cognitive theories of SA (e.g., Clark \& Wells, 1995; Wells, 2013) and approaches to management of other anxiety problems following TBI (Williams et al., 2003; Soo \& Tate, 2009). Consequently, an understanding of SA following TBI in adults must be guided by research which explores the role of potentially relevant neurological, cognitive, situational and psychological factors to guide assessment, formulation and intervention during acute and long-term rehabilitation.

A broad range of psychological variables may be important in SA following TBI (Soo et al., 2012). Locus of control (LoC), the beliefs a person holds about how the behaviour of themselves and others influences their health (Wallston, Stein, \& Smith, 1994), has been associated with SA (Cloitre, Heimberg, Liebowitz, \& Gitow, 1992; Kennedy, Lynch, \& Schwab, 1998) and emotional problems in people who have experienced TBI (Moore \& Stambrook, 1992). Self-efficacy, the beliefs people hold about their capabilities is also associated with SA (Leary \& Atherton, 1986) and is predictive of global life satisfaction following TBI (Cicerone \& Azulay, 2007). Low self-esteem is also linked to SA (Ritter, Ertel, Beil, Steffens, \& Stangier, 2013). Though debate continues around the consistency of the construct, self-esteem is generally defined as the global, subjective and emotional 
judgements one holds about the self (Guindon, 2002), which are activated and reinforced in social situations and contribute to fear of negative evaluation (Wells, 2013; Clark \& Wells, 1995; Rapee \& Spence, 2004). People who have experienced TBI have been found to have lower self-esteem (Ponsford, Kelly, \& Couchman, 2014) and self-esteem has been shown to predict psychosocial outcomes following TBI (Tate \& Broe, 1999).

Furthermore, fear of negative evaluation may mean that people with SA perceive or experience higher levels of stigma (Anderson, Jeon, Blenner, Wiener, \& Hope, 2015; Clark \& Wells, 1995). People who are socially anxious may be rejected or perceived negatively, particularly if anxiety related behaviours (e.g., gripping hands together, avoiding eye contact) compound the anxiety symptoms or impair social performance (Wells, 2013; Rapee \& Spence, 2004). As highlighted above, the physical and cognitive consequences of TBI may add further challenges to social interactions. Qualitative research has suggested stigma may be a potential factor affecting wellbeing following TBI, with participants highlighting the lack of public understanding about the consequences of TBI and how this impacts on their social engagement (Morris et al., 2005; Nochi, 1998). Furthermore, perceived stigma is strongly associated with anxiety in people with chronic physical conditions (Alonso et al., 2008) and epilepsy (Beyenburg, Mitchell, Schmidt, Elger, \& Reuber, 2005).

In conclusion, despite the theoretical rationale for SA following TBI presented by Soo et al. (2012) and Moore et al., (2006), present understanding of SA following TBI is limited given the limited available research. No research to date has explored psychological factors which might contribute to the development of SA following TBI to provide guidance for assessment and intervention. While it is recognised that psychological problems may predate a brain injury (Williams et al., 2003), people who have experienced TBI may be at greater risk of developing SA due to the nature of the factors described above. Consequently, the present study aimed to investigate psychological factors associated with SA following TBI, 
alongside clinical and demographic variables. It was hypothesised that psychological variables such as LoC, self-efficacy, self-esteem and perceived stigma would account for an additional and significant amount of variance in SA, above that explained by demographic and clinical variables.

\section{Methods}

\section{Design}

The study employed a quantitative, cross-sectional within-subjects design to explore factors predicting SA after TBI. Self-report questionnaires were used as the data collection method. If required, participants were given support from the lead researcher to complete the questionnaires.

\section{Participants}

Participants were required to have sustained a TBI, defined as an injury caused by an external or mechanical force (Morton \& Wehman, 1995), to differentiate from the broader categorisation of ABI. Participants in the study were required to be aged over 18 and able to read English (due to lack of the validated measures in other languages). Participants were required to have sustained a TBI after the age of 16 to allow for specific examination of factors in relation to adults, as other developmental factors are likely to influence cognitive and psychological outcomes following TBI experienced in childhood or adolescence (Anderson et al., 2006; Catroppa, Anderson, Morse, Hariou, \& Rosenfeld, 2008). Given the focus on social functioning, participants were required to be living in the community (either at home or in long-term supported accommodation) rather than a medical ward or residential rehabilitation unit. Participants were also required to have capacity to consent to participation in the study.

An a priori power calculation for multiple regression analysis, assuming a medium effect size of $0.15,80 \%$ power and an alpha level set at $p=.05$, suggested that a sample of 
between 92 and 139 would be required. A total of 98 participants were recruited, with 54 participants completing the questionnaires online and 44 submitting paper copies provided via National Health Service (NHS) or third sector services. Five participants who completed the study online were excluded from the analysis as they described their injury as an ABI (e.g., subarachnoid haemorrhage) rather than a TBI and therefore did not meet all the inclusion criteria. A further eight participants were excluded as a significant amount of questionnaire data (more than $10 \%$, as recommended by Bennett, 2001) were missing.

Therefore, a total of 85 participants provided data for the analyses. Participants ranged in age from 19 to 81 years $(M=42.4, S D=13.335)$. The final sample included $63.5 \%$ $(n=54)$ males and $32.9 \%(n=28)$ females, with $3.5 \%(n=3)$ reporting "Other / Prefer not to say". Further demographic information is shown in Table 1.

[INSERT TABLE 1 HERE]

Due to ethical and resource constraints, medical data regarding severity of injury were not available. Participants were asked to report the length of time they were in hospital for after their injury $(M=16.529$ weeks, $S D=32.120)$ and time since injury $(M=7.719$ years, $S D=8.733)$

\section{Measures}

Outcome variable. The Social Phobia Inventory (SPIN; Connor et al., 2000) was used as the outcome measure for the study. The SPIN is a 17-item self-report measure of three domains of SA; fear, avoidance and physiological discomfort. Responses are scored from 0 (not at all) to 4 (extremely), with a maximum total score of 68 indicating high levels of SA. A cut-off score of 19 is recommended by the authors to distinguish those with SA. High levels of internal consistency $(\alpha=.95)$ and test-retest reliability $(r=.86)$ have been demonstrated (Antony, Coons, McCabe, Ashbaugh, \& Swinson, 2006; Connor et al., 2000). Although the measure has not been used in a TBI population in any published research to 
date, it has been utilised with patients with multiple sclerosis (Poder et al., 2009) and is recommended by guidance provided by NICE (2013) for use in NHS services within the UK. The SPIN's face validity and brevity make it the most appropriate measure from available measures of SA.

Predictor variables. The Applied Cognition measure (Neuro-QOL, 2012) was used to assess subjective severity of cognitive problems. This 18 -item measure assesses perceived difficulties in everyday cognitive domains including memory, attention, and decisionmaking. Responses range from never (1) to very often (5), with a maximum score of 90. High levels of internal consistency $(\alpha=.95)$ and test-retest reliability $(r=.82)$ have been demonstrated in samples of patients with a range of neurological problems (e.g., stroke, epilepsy, Parkinson's disease) but data are not available for a TBI sample (Neuro-QOL, 2010).

Form C of the Multidimensional Health Locus of Control (MHLoC, Wallston, Stein, \& Smith, 1994) assesses belief in one's ability to control health outcomes, in relation to a specific illness or disease. The measure encompasses four subscales of LoC: internal; chance; powerful others (doctors) and powerful others (other people). Responses are scored from 1 (strongly disagree) to 6 (strongly agree), with a higher subscale score indicating higher LoC (no total score is calculated). Wallston et al. (1994) demonstrated acceptable levels of internal consistency and test-retest reliability for each subscale; internal $(\alpha=.79-.87 ; r=.80)$, chance $(\alpha=.79-.82 ; r=.72)$, doctors $(\alpha=.71 ; r=.58)$ and other people $(\alpha=.70-.71 ; r=$ 40). Despite its focus on control over one's specific illness or disease (Wallston, 2005), no published research has used Form $\mathrm{C}$ with a TBI population. However, Forms A and B of the MHLoC have been used in previous TBI research (Bedard et al., 2005; Moore \& Stambrook, 1992), and Form C has been used to assess LoC following spinal cord injury (Waldron et al., 2010). 
The Rosenberg Self-Esteem Scale (RSES, 1965) is a 10-item measure, with responses recorded on a 0 to 3 scale (reverse coded on some items) so that a low score on the RSES indicates low self-esteem. The RSE demonstrates high internal consistency ( $\alpha=.92)$, and test-retest reliability $(r=.85)$ after two weeks (Rosenberg, 1979). This measure has been used to examine self-esteem in people who have experienced a TBI (e.g., Anson \& Ponsford, 2006a; Anson \& Ponsford, 2006b; Ponsford et al., 2014).

The Self-Efficacy for Symptom Management Scale (Cicerone \& Azulay, 2007) assesses confidence in managing common challenges and seeking support after TBI. The 13items measure is scored 1 (not at all confident) to 10 (totally confident), with a maximum total score of 130 indicating high self-efficacy. High levels of internal consistency $(\alpha=.93)$ and test-retest reliability $(r=.93)$ have been demonstrated (Cicerone \& Azulay, 2007).

The Stigma scale published by Neuro-QOL (2012) is a 24-item measure which examines a person's perceptions of self and publically enacted prejudice and discrimination experienced as a result of neurological problems. Responses are scored from 1 (never) to 5 (always), with a maximum score of 120 indicating high levels of perceived stigma. High levels of internal reliability $(\alpha=.91)$ and test-retest reliability $(r=.82)$ have been demonstrated in samples of patients with a range of neurological problems (e.g., stroke, epilepsy, Parkinson's disease) but no data are available for a TBI sample (Rao et al., 2009). For the purposes of the study, the word 'illness' was replaced with the term 'brain injury' on each item of the questionnaire.

The Hospital Anxiety and Depression Scale (HADS; Zigmond \& Snaith, 1983) was designed for use with people with physical health problems and assesses anxiety and depression without relying on somatic symptoms of illness (e.g., fatigue, insomnia). The 14item measure is scored on a 0 to 3 scale, appropriately coded so that a higher score on each subscale indicates a more severe problem with anxiety or depression. A review of its 
psychometric properties reports good levels of internal consistency on the anxiety $(\alpha=.68$ .93 ) and depression $(\alpha=.67-.9)$ subscales across a variety of settings (Bjelland, Dahl, Haug, \& Neckelmann, 2002), with similar findings reported by Whelan-Goodinson, Ponsford and Schönberger (2009) with a TBI sample (depression $\alpha=.88$; anxiety $\alpha=.92$ ). The HADS has been used to measure depression and anxiety after TBI in a number of published studies (e.g., Anson \& Ponsford, 2006a; Anson \& Ponsford, 2006b; Downing, Stolwyk, \& Ponsford, 2013).

\section{Procedure}

Potential participants were identified and recruited through professionals working in neuropsychology teams across nine NHS Trusts in the North-West of England and third sector organisations relevant to TBI. Participants were also able to self-refer into the study and could opt to complete an online version of the study made using Qualtrics Survey Software (Qualtrics, 2013), which provided security and encryption for online information. The study was advertised via social networking websites and posters displayed in NHS neuropsychology services and third sector organisations.

Prior to completing the questionnaires, participants were required to complete a screening and consent form based on the inclusion and exclusion criteria outlined above. On the online version of the study, participants were only able to progress onto the questionnaires if they answered each item of the consent form. Capacity to consent and participate in the study was assumed in line with the UK Mental Capacity Act (2005). Participants had the option of completing the questionnaires online or on paper posting them to the lead researcher. To reduce bias, the online study was set to present questionnaires in a random order. 


\section{Ethical Approval}

The study received ethical approval from the UK NHS National Research Ethics Service, followed by local approval from the Research and Development Departments of each NHS Trust involved in recruitment. This approval also covered participants recruited through third sector organisations and online.

\section{Data Analysis Strategy}

Data were analysed using IBM SPSS Statistics version 20. All questionnaires were scored in accordance with scale instructions and reverse coded as required. Relationship status was recoded to a binary variable (i.e., yes / no). Due to its descriptive nature, cause of injury was not entered into the regression model. Anxiety (measured by HADS) was not entered into the regression model as it correlated too highly with the outcome variable $(r=$ $.726, p<.001)$ and, as it is conceptually similar, would have reduced the variance available to other variables. Additionally, depression was considered a clinical variable rather than a psychological one, due to the focus of the HADS on measuring clinical difficulties associated with depression.

Throughout the study, a $p$ value of .05 was used as a threshold for statistical significance in line with convention (Field, 2013). Furthermore, the decision was taken not to use Bonferroni corrections to counteract multiple comparisons as this would have resulted in a very low $p$ value and significantly reduced statistical power.

Hierarchical multiple regression analysis was used to explore the study hypothesis. Variables were entered into the model in three blocks; demographic, clinical, psychological. Consistent with the available theoretical rationale for SA following TBI discussed above, this allowed for examination of the amount of variance in SA which could be explained by psychological variables, above that explained by demographic and clinical variables. 
In determining what variables were entered into the regression model, decisions for subset selection were made based on effect size instead of $p$ values. While use of $p$ values is common, effect sizes are less reliant on sample size (Coe, 2002). Given the relatively low sample size in this study $(n=85)$, variables were included in the multiple regression analysis if a small effect size was observed (i.e., $r>.1$; Cohen, 1988). This threshold was chosen to allow an inclusive, exploratory approach which minimised the risk of overlooking emerging effects of small magnitude (Hemphill, 2003).

\section{Results}

\section{Data Preparation and Analysis}

It did not appear that there were any systematic biases or patterns to the missing data as defined by Graham (2009), with 34 cases (40\% of the sample) having incomplete data across 42 (34.43\%) of the variables. Little's (1988) Missing Completely At Random (MCAR) test was not significant $\left(X^{2}=1921.880, d f=3105, p=1.000\right)$, suggesting that the null hypothesis of data being missing randomly could be assumed.

Even after removing the eight cases missing more than $10 \%$ of data, the number of other cases missing smaller amounts of data was high. Listwise or pairwise deletion methods were not considered appropriate as this would have seen a large proportion of cases deleted, thereby reducing sample size and power in addition to potentially introducing bias into the multiple regression model. Consequently, multiple imputation was conducted with the data provided by 85 participants to analyse missing data and input substituted values (Rubin, 1987; Schaffer, 1997). Five iterations of imputation were performed (Schaffer, 1997).

\section{Clinical Characteristics of Sample}

Descriptive statistics for all self-report measures used in the study are provided in Table 2. As can be seen in Table 2, all measures demonstrated acceptable levels of internal consistency ( $\alpha>$.6; Hair, Anderson, Tatham \& Black, 2006). 


\section{[INSERT TABLE 2 HERE]}

Independent samples t-test showed no significant difference on SPIN scores between participants who completed the questionnaire online compared to those who did not $(t(91)=$ $.635, p=.527)$. Using the cut-off scores for social anxiety as recommended by the authors of the SPIN (Connor et al, 2000), most participant scores (47.1\%) lay in the 'None' category (> 20). A further 15 participants (17.6\%) scored within the 'Mild' category, 13 (15.3\%) scored within the 'Moderate' category, $10(11.8 \%)$ scored in the 'Severe' category, and 7 (8.2\%) participants were categorised as 'Very Severe'. Using the cut-offs provided by the scale authors (Zigmond \& Snaith, 1983), 70.6\% of the sample showed clinically significant levels of anxiety (with $21.2 \%$ in the severe category) while $63.5 \%$ of the sample showed clinically significant levels of depression (with $20 \%$ in the severe category).

\section{Correlational Analysis}

Correlational analysis (Pearson's $r$ ) was conducted on the pooled dataset comprising of all iterations of the multiple imputation process (Rubin, 1987). Correlations are shown in Tables 3 and 4 .

\section{[INSERT TABLE $3 \& 4$ HERE]}

The following variables correlated significantly $(p<.05)$ with higher SA scores on the SPIN: not being employed $(r=.239, p=.028)$; higher levels of cognitive problems $(r=$ $.476, p<.001)$; higher levels of internal $(r=.248, p=.022)$ and chance $(r=.217, p=.046)$ LOC; lower self-esteem $(r=-.441, p<.001)$; lower self-efficacy $(r=-.472, p<.001)$; higher perceived stigma $(r=.654, p<.001)$; higher levels of anxiety $(r=.726, p<.001)$ and higher levels of depression $(r=.516, p<.001)$. Age, gender, time since TBI, time in hospital, living alone, relationship status and the two Powerful Others subscales of the MHLoC (Doctors and Others) did not significantly correlate with SA scores. 


\section{Hierarchical Multiple Regression Analysis}

Hierarchical multiple regression analysis was conducted to examine if the predictor variables were able to explain the variance in SA scores. Predictor variables which correlated with SA demonstrating a small effect size or above (Pearson's $r>0.1$ ) were entered into the regression model. Predictor variables were entered into the regression model in three blocks: (a) demographic variables (gender, employment status); (b) clinical variables (time since TBI, perceived cognitive problems, depression); (c) psychological variables (MHLoC internal, MHLoC chance, self-esteem, self-efficacy, perceived stigma).

The overall model was significant, both with the original dataset $(F(2,63)=5.918, p$ $<.001$, explaining $51.8 \%\left(R^{2}=.518, R^{2}{ }_{\text {adj }}=.431\right)$ of the variance in SA scores and across all five imputations of missing data, with $F(2,82)$ values ranging from 8.006 to 8.799 , with all values of $p<.001$. The amount of variance in SA scores explained ranged from $52 \%\left(R^{2}=\right.$ $\left..520, R_{a d j}^{2}=.455\right)$ to $54.3 \%\left(R^{2}=.543, R_{a d j}^{2}=.481\right)$ of the variance in SA scores.

The Durbin-Watson values across the imputations ranged from 1.962 to 2.000 compared to the value from the original data of 1.846 , and therefore it was assumed there was no autocorrelation of residuals (Field, 2013). Examination of the VIF, tolerance and eigenvalues confirmed that there was no evidence of collinearity within the dataset (Bowerman \& O'Connell, 1990; Menard, 1995; Field, 2013). Graphical representation of the data suggested that assumptions of homoscedasticity and normally distributed residuals could be upheld.

Block one (demographic variables) accounted for $10.3 \%\left(R^{2}=.103, R_{\text {adj }}^{2}=.074, p=\right.$ $.033)$ of the variance in SA scores in the original dataset, rising to between $11.9 \%\left(R^{2}=.119\right.$, $\left.R_{\text {adj }}^{2}=.097, p=.006\right)$ and $14.7 \%\left(R^{2}=.147, R_{\text {adj }}^{2}=.126, p=.001\right)$ following imputation. The addition of block two (clinical variables) made a significant contribution to the model, increasing the total variance explained to $36.1 \%\left(\Delta R^{2}=.259, p<.001\right)$ for the original 
dataset and between $39.8 \%\left(\Delta R^{2}=.279, p<.001\right)$ and $41.3 \%\left(\Delta R^{2}=.280, p<.001\right)$

following imputation, with significant changes in $F(p<.001)$ for both original and imputed data. Within this block of variables, standardised beta values across imputations indicated that higher levels of perceived cognitive problems $(\beta=.249$ to $.253, p=.012)$ and depression $(\beta=.348$ to $.367, p<.001)$ were significant independent predictors of higher reported SA, with time since injury not statistically significant $(\beta=.055$ to $.064, p=.516)$.

The addition of block three (psychological variables) also made a significant contribution to the overall model, explaining an additional $15.7 \%\left(\Delta R^{2}=.157, p<.001\right)$ of the total variance for the original dataset and between $12.2 \%\left(\Delta R^{2}=.122, p<.001\right)$ and $13 \%$ $\left(\Delta R^{2}=.130, p<.001\right)$ for each imputation. The change in $F$ associated with the addition of block three was statistically significant for both original $(p=.007)$ and imputed data $(p=$ .002 to .004$)$.

For individual predictors of SA, the overall model including all three blocks (and based on data pooled from all imputations) indicated that only higher levels of perceived stigma significantly predicted higher levels of SA $(B=.274, \beta=.334$ to $.341, t=2.789, p=$ $.005)$. In the final model, reported cognitive problems and depression ceased to meet criteria for statistical significance. In terms of the amount of variance explained by the other psychological variables, standardised beta values across imputations suggested that the internal subscale of the MHLoC $(\beta=.116$ to .123$)$ and self-esteem $(\beta=-.090$ to -.124$)$ predicted more variance in SA than self-efficacy $(\beta=-.050$ to -.070$)$ and the chance subscale of the MHLoC ( $\beta=.047$ to .061$)$. However, internal LoC and self-esteem were not statistically significant independent predictors of SA.

\section{Discussion}




\section{Key findings}

The present study examined psychological variables associated with SA following

TBI. The overall regression model was significant, and the hypothesis that psychological variables would account for a significant proportion of the variance in SA was supported. Over half the sample (52.9\%) showed clinically significant levels of SA, as defined using the cut-off provided by the scale author (Connor et al., 2000). This is substantially higher than both the estimated prevalence rate of $12 \%$ observed in the general population (NICE, 2013) and the rate of $30.6 \%$ found with a sample of people diagnosed with another chronic neurological condition, multiple sclerosis (Poder et al., 2013).

Before psychological variables were added to the regression model, severity of perceived cognitive problems and depression were significant predictors of greater levels of SA. Depression is often comorbid with SA in the general population (Ohayon, Schatzberg, 2010), with negative beliefs about the self and others central to cognitive understandings of both presentations. Additionally, it is understandable that people who perceive more severe levels of cognitive impairment might have more negative evaluations of themselves as social objects, thereby experiencing higher levels of social anxiety. This has been highlighted in qualitative research with people who have experienced TBI (Morris et al., 2005; Nochi, 1998); worry that other people will think they are slow or stupid has the potential to increase anxiety in social situations. Anxiety may also further reduce available attentional and cognitive processing capacity (which may already be decreased following TBI), thereby heightening and maintaining the problems experienced and the development of avoidance patterns. In this respect, perception of cognitive problems and low mood are clearly important clinical factors to consider in understanding the development and maintenance of SA.

The addition of psychological variables (MHLoC internal, MHLoC chance, selfesteem, self-efficacy, perceived stigma) made a significant additional contribution to the 
amount of variance explained, suggesting that psychological variables are important factors in the development of SA following TBI in addition to demographic and clinical variables. In the overall model (i.e., where the available variance was shared across a greater number of predictor variables), only perceived stigma was a significant independent predictor of SA. All other psychological variables explained some variance in SA, with internal LoC and selfesteem predicting a greater amount of variance than self-efficacy and chance LoC. Although internal LoC and self-esteem did not reach statistical significance as independent predictors, this may be due to the relatively small sample size employed in the study and further examination is warranted. Nevertheless, when self-esteem, self-efficacy and LoC are combined with perceived stigma they explain a significant amount of variance in SA, above and beyond that explained by demographic and clinical factors such as depression and perceived cognitive problems. It should also be noted that adding these variables as the final block in the regression model provides a particularly rigorous and robust test of their predictive power.

As outlined above, there is no previous research directly examining the role of psychological variables in the development of SA following TBI. However, the results are in keeping with theoretical and empirical understandings of psychological and psychosocial functioning following TBI. Indeed, there is growing consensus that psychological wellbeing and psychosocial functioning following TBI is influenced by a broad range of factors, with psychological variables playing a key role alongside cognitive, neurological and demographic factors (Soo et al., 2012; Moore et al., 2006; Kendall \& Terry, 1996).

Furthermore, the emergence of perceived stigma as a significant independent predictor is a key finding. This offers support for Kendall and Terry's (1996) model of psychosocial functioning after TBI, in which perceived stigma is proposed as a key factor 
affecting primary appraisal (i.e., how events are appraised), which subsequently affects secondary appraisal (i.e., a person's beliefs around how well they can cope with an event). This finding is also consistent with theoretical models highlighting how aversive social experiences are a key factor in the development of SA (Rapee \& Spence, 2004). The cognitive model of SA, proposed by Clark and Wells (1995) and updated by Wells (2013), proposes that social situations activate negative automatic thoughts based on assumptions around perceived danger in social situations. Negative evaluations of how the self is processed as a social object (i.e., how the person thinks they appear to others) are often inaccurate or exaggerated and can lead to safety behaviours (e.g., avoidance), which serve to reinforce the beliefs (Wells, 2013). Safety behaviours maintain and exacerbate the problems by perpetuating the beliefs that social interactions will lead to negative outcomes (Clark \& Wells, 1995; Wells, 2013; Banerjee \& Henderson, 2001). Since social experiences are key to the development and maintenance of SA, it is consistent that perceived stigma would play a key role in the development of SA. As discussed above, greater levels of perceived cognitive problems and reduced mood are also likely to be important factors in the development of such problem cycles.

These findings are also consistent with social models of disability, which highlight the need to focus on the societal context of impairment (Oliver, 1983; 2004). Instead of focusing on the functional impairments of the individual, the social model considers disability to be caused by the economic, cultural and environmental barriers which are faced by people with physical or cognitive impairments. Consistent with the findings of the present study, Oliver (2004) discusses how cultural norms around disability, which view impairment as unattractive and unwanted, negatively impact people by creating stigmatising, discriminatory environments which devalue and actively disable people with impairments, thereby causing psychological distress. Individualistic psychiatric or psychological approaches often fail to 
take this into account, instead conceptualising psychological problems as a consequence of the impairment itself and focusing on the need for people to seek treatment or adapt to the disabling environment (Simpson \& Thomas, 2014; Simpson, McMillan \& Reeve, 2013).

Moreover, people who develop impairments throughout their lives have been raised within these cultural norms (Oliver, 2004). The term psychoemotional disablism refers to how negative social interactions can lead to negative societal stereotypes about what it means to have an impairment being internalised, which can limit the coping resources people have to draw on and lead to reduced participation in society (Reeve, 2012; Simpson et al., 2013). Research has highlighted how stigma and poor understanding are key problems in relation to TBI (e.g., Linden \& Boylan, 2010; McClure, 2011; Guilmette \& Paglia, 2004). In emphasising the role of stigma in the development of SA following TBI, this study highlights the importance of considering the societal and cultural factors influencing a person's experience of impairment following TBI, guiding intervention at both an individual and social level.

\section{Clinical implications}

These findings have various implications for health professionals. It appears that SA is a problem following TBI and the application of cognitive models of SA to therapeutic work may be a useful way to conceptualise problems with psychosocial functioning following TBI. The clear role for psychological factors such as self-esteem, self-efficacy and LoC in the development of SA following TBI suggests a need to consider these variables during physical and cognitive assessment and rehabilitation, supporting the development of an individual's psychological resilience during the complex process of recovery from TBI.

In particular, the significant role which stigma plays in the development of SA following TBI highlights the importance of developing contextually inclusive formulations (BPS, 2011) which explore the reactions people experience from others, in addition to the 
individual psychological factors which affect how responses of other people are perceived. By considering the ways in which disability is constructed by the discriminatory social context faced by people who have experienced TBI and not focusing solely on the individual, interventions which challenge the lack of knowledge and negative attitudes around TBI (Linden \& Boylan, 2010; McClure, 2011; Guilmette \& Paglia, 2004) can begin to address the barriers, discrimination and stigma which are often imposed through entrenched societal and cultural norms (Simpson \& Thomas, 2014; Oliver, 2004). Indeed, the precise nature of the stigma being experienced is important. For example, this study highlights the importance of perceived cognitive impairment; specific cognitive impairments following TBI may be misunderstood as a reduction in overall intellectual ability and functional independence. Educational programmes could highlight the difference between general intellectual ability and the types of cognitive problems that can be experienced after TBI, along with ways in which the individual and the people around them can reduce the impact these problems might have on their life.

\section{Limitations and Implications for Future Research}

It is recognised that the use of a self-selecting sample may have introduced some bias to the sample. The study also focused exclusively on people living in the community. A different pattern of results may be evident with a sample in the earlier stages of recovery and future research may be useful in exploring how different kinds of interactions with professionals at an early stage affect the development of SA. Moreover, this study focused on TBI to explore specific issues relating to this population. Further research which widens the scope of the study to include people with other kinds of acquired brain injuries may increase the generalisability of these findings to clinical practice.

Furthermore, the cross-sectional nature of the study limits the potential for understanding how SA and the other variables under examination may change over time. 
Consequently, future research which utilises a longitudinal or prospective design would be of value. In addition, the use of multiple regression in the current study assumes a linear relationship between variables. However, as psychological variables have been shown to play a significant role in the development of SA, use of more advanced statistical techniques (e.g., structural equation modelling) would be useful next step following this study. For example, the regression model suggests that perceived stigma is predictive of SA, however it is possible that this is a bi-directional relationship and that people who are more anxious in social situations are likely to be hyper-vigilant to threat, thereby perceiving higher levels of stigmatising behaviour from others. Further research analysing hypothesised pathways between factors will allow for a more detailed understanding of the complex bi-directional interactions between predictor and outcome variables. This will be useful in guiding intervention, in that targeting particular variables (e.g., self-esteem) in therapy may help to reduce the amount of stigma which is perceived, mitigating its effect on SA.

Furthermore, the lack of characterisation of the sample in terms of objective severity of injury and cognitive impairment is a limitation of the study. Perceived severity of cognitive problems may not be accurate and the self-selected sample may potentially result in a less impaired group. However, injury variables and degree of cognitive impairment do not fully account for variance in psychosocial adjustment following TBI (Antonak et al., 1993) and appraisal of cognitive limitations has been shown to moderate the relationship between injury severity and psychosocial function (Kervick \& Kaemingk, 2005). Therefore, by assessing subjective severity of cognitive problems using a self-report measure, the degree to which an individual's appraisal of their cognitive problems can contribute to SA can be explored. Future research employing other methods of assessing neurological and cognitive variables would be useful, for example using neuropsychological assessments to assess impairments in specific cognitive domains, or consulting medical records to obtain specific 
details of TBI severity. Further examination of other relevant psychological variables such as appraisal and coping style would also be of value, given the relevance of such factors in relation to wellbeing following TBI (Anson \& Ponsford, 2006a; Kendall \& Terry, 1996).

The present study also did not explore situational factors in detail. Although living alone and being in a relationship did not significantly correlate with SA in this study, future research might address environmental factors hypothesised to be of importance for psychosocial wellbeing following TBI (Kendall \& Terry, 1996). For example, social contact, family dynamics and perceptions of support from others might be important variables to consider in the development of SA following TBI, particularly as social learning theories of SA suggest that experience of aversive situations and lack of modelling of adaptive coping strategies for managing social situations are key to the development of SA (Rapee \& Spence, 2004). Longitudinal research examining relationships post-TBI may be extremely useful in understanding SA and psychosocial wellbeing more broadly.

Even considering the limitations discussed above, the present study is the first to examine factors associated with SA following TBI. The findings of this study highlight the importance of considering SA in this population, particularly when considering rehabilitation adjustment following TBI. The significance of perceived stigma as a predictor of SA is an important finding in this context, highlighting a clear role for clinical psychologists and other rehabilitation professionals to integrate social models of disability into their practice and make a valued contribution to the psychological wellbeing of people who have experienced TBI.

\section{Conclusion}

The current study explored factors predicting SA following TBI. Hierarchical multiple regression was used to examine the extent to which demographic, clinical and psychological variables predicted scores on a measure of SA. Psychological variables, 
particularly perceived stigma, explained a significant proportion of the variance in SA.

Therefore it is proposed that psychological variables are important factors affecting the development of SA following TBI, above and beyond demographic and clinical variables.

The study provides empirical support to the theoretical rationale for SA following TBI proposed by Soo et al. (2012) and Moore et al. (2006), highlighting the potential application of Kendall and Terry's (1996) model for psychosocial adjustment. Further research is required to examine the complex relationships between such variables using a more stable regression model, and to explore in more detail other variables which may have an influence on SA using more advanced statistical techniques which allow for the examination of nonlinear relationships. 


\section{References}

Alonso, J., Buron, A., Bruffaerts, R., He, Y., Posada, Villa, J., Lepine, J. P., ... \& Von Korff, M. (2008). Association of perceived stigma and mood and anxiety disorders: results from the World Mental Health Surveys. Acta Psychiatrica Scandinavica, 118(4), 305-314. doi:10.1111/j.1600-0447.2008.01241.x

American Psychiatric Association. (2013). Diagnostic and statistical manual of mental disorders (5th ed.). Washington DC: American Psychiatric Association.

Anderson, K. N., Jeon, A. B., Blenner, J. A., Wiener, R. L., \& Hope, D. A. (2015). How people evaluate others with social anxiety disorder: A comparison to depression and general mental illness stigma. American Journal of Orthopsychiatry, 85(2), 131-138. doi:10.1037/ort0000046

Anderson, V.A., Catroppa, C., Dudgeon, P., Morse, S.A., Haritou, F., Rosenfeld, J.V. (2006). Understanding predictors of functional recovery and outcome 30 months following early childhood head injury. Neuropsychology, 20(1), 42-57. doi:10.1037/0894-4105.20.1.42

Anson, K., \& Ponsford, J. (2006a). Coping and Emotional Adjustment Following Traumatic Brain Injury. The Journal of Head Trauma Rehabilitation, 21(3). doi:10.1097/00001199200605000-00005

Anson, K., \& Ponsford, J. (2006b). Who benefits? Outcome following a coping skills group intervention for traumatically brain injured individuals. Brain Injury, 20(1), 1-13. doi:10.1080/02699050500309791

Antonak, R. F., Livneh, H., \& Antonak, C. (1993). A review of research on psychosocial adjustment to impairment in persons with traumatic brain injury. The Journal of Head Trauma Rehabilitation, 8(4). doi:10.1097/00001199-199312000-00009 
Antony, M. M., Coons, M. J., McCabe, R. E., Ashbaugh, A., \& Swinson, R. P. (2006). Psychometric properties of the social phobia inventory: Further evaluation. Behaviour Research and Therapy, 44(8), 1177-1185. doi:10.1016/j.brat.2005.08.013

Banerjee, R., \& Henderson, L. (2001). Social-cognitive factors in childhood social anxiety: A preliminary investigation. Social Development, 10(4), 558-572. doi:10.1111/14679507.00180

Bedard, M., Felteau, M., Gibbons, C., Klein, R., Mazmanian, D., Fedyk, K., \& Mack, G. (2005). A mindfulness-based intervention to improve quality of life among individuals who sustained traumatic brain injuries: One-year follow-up. The Journal of Cognitive Rehabilitation, 25(13), 8-13. doi:10.1080/0963828031000090489

Bennett, D. A. (2001). How can I deal with missing data in my study? Australian and New Zealand Journal of Public Health, 25(5), 464-469. doi:10.1111/j.1467-842X.2001.tb00294.x

Beyenburg, S., Mitchell, A. J., Schmidt, D., Elger, C. E., \& Reuber, M. (2005). Anxiety in patients with epilepsy: Systematic review and suggestions for clinical management. Epilepsy \& Behavior, 7(2), 161-171. doi:10.1016/j.yebeh.2005.05.014

Bjelland, I., Dahl, A. A., Haug, T. T., \& Neckelmann, D. (2002). The validity of the Hospital Anxiety and Depression Scale. An updated literature review. Journal of Psychosomatic Research, 52(2), 69-77. doi:10.1016/s0022-3999(01)00296-3

Bowerman, B. L., \& O’Connell, R. T. (1990). Linear statistical models: An applied approach. Belmont, CA: Duxbury.

British Psychological Society (2008). Conducting research with people not having the capacity to consent to their participation. Leicester, England: British Psychological Society.

British Psychological Society (2011). Good Practice Guidelines on the use of psychological formulation. Leicester, England: British Psychological Society. 
Brockfield, K. C., Perini, S. J., and Rapee, R. M. (2014). Social Anxiety and Social Anxiety Disorder Across Cultures. In S. G. Hofmann, P. M. DiBartolo (Eds.), Social Anxiety: Clinical, Developmental, and Social Perspectives. London, England: Academic Press.

Bryant, R. A., O' Donnell, M. L., Creamer, M., McFarlane, A. C., Clark, C. R., \& Silove, D. (2010). The psychiatric sequelae of traumatic injury. American Journal of Psychiatry, 167(3), 312320. doi:10.1176/appi.ajp.2009.09050617

Catroppa, C., Anderson, V. A., Morse, S. A., Haritou, F., \& Rosenfeld, J. V. (2008). Outcome and Predictors of Functional Recovery 5 Years Following Pediatric Traumatic Brain Injury (TBI). Journal of Pediatric Psychology, 33(7), 707-718. doi:10.1093/jpepsy/jsn006

Cicerone, K. D., \& Azulay, J. (2007). Perceived self-efficacy and life satisfaction after traumatic brain injury. The Journal of Head Trauma Rehabilitation, 22(5), 257-266.

doi:10.1097/01.htr.0000290970.56130.81

Clark, D. M., \& Wells, A. (1995). A cognitive model of social phobia. In M. R. Liebowitz (Eds.), Social phobia: Diagnosis, assessment, and treatment, (pp. 69-93). New York, NY: Guilford Press.

Cloitre, M., Heimberg, R. G., Liebowitz, M. R., \& Gitow, A. (1992). Perceptions of control in panic disorder and social phobia. Cognitive Therapy and Research, 16(5), 569-577. doi:10.1007/BF01175142

Coe, R. (2002). It's the Effect Size, Stupid: What effect size is and why it is important. Paper presented at the Annual Conference of the British Educational Research Association, University of Exeter, England. Retrieved from www.cem.org/attachments/ebe/ESguide.pdf/

Cohen, J. (1988). Statistical power analysis for the behavioral sciences $\left(2^{\text {nd }}\right.$ ed.). Hillsdale, NJ: Erlbaum. 
Connor, K. M., Davidson, J., Churchill, L. E., Sherwood, A., Weisler, R., \& Fox, E. (2000).

Psychometric properties of the Social Phobia Inventory (SPIN): New self-rating scale. The British Journal of Psychiatry, 176(4), 379-386. doi:10.1192/bjp.176.4.379

Crome, E., Grove, R., Baillie, A. J., Sunderland, M., Teesson, M., \& Slade, T. (2014). DSM-IV and DSM-5 social anxiety disorder in the Australian community. Australian \& New Zealand Journal of Psychiatry, 49(3), 227-235. doi:10.1177/0004867414546699

Downing, M. G., Stolwyk, R., \& Ponsford, J. L. (2013). Sexual Changes in Individuals With Traumatic Brain Injury. The Journal of Head Trauma Rehabilitation, 28(3), 171-178. doi:10.1097/HTR.0b013e31828b4f63

Field, A. (2013). Discovering Statistics using IBM SPSS Statistics. London, England: Sage.

Goldstein, L. H., \& McNeil, J. E. (2012). Clinical Neuropsychology. Sussex, England: John Wiley \& Sons.

Gould, K.R., Ponsford, J.L., Johnston, L., Schönberg, M. (2011). The nature, frequency and course of psychiatric disorders in the first year after traumatic brain injury: a prospective study. Psychological Medicine, 41(10), 2099-2109. doi:10.1017/S003329171100033X

Gracey, F., Evans, J. J., \& Malley, D. (2009). Capturing process and outcome in complex rehabilitation interventions: A "Y-shaped" model. Neuropsychological Rehabilitation, 19(6), 867-890. doi:10.1080/09602010903027763

Graham, J. W. (2009). Missing Data Analysis: Making It Work in the Real World. Annual Review of Psychology, 60(1), 549-576. doi:10.1146/annurev.psych.58.110405.085530

Guilmette, T. J., \& Paglia, M. F. (2004). The public's misconceptions about traumatic brain injury: A follow up survey. Archives of Clinical Neuropsychology, 19(2), 183-189. doi:10.1016/s0887$6177(03) 00025-8$

Guindon, M. (2002). Toward accountability in the use of the self-esteem construct. Journal of Counseling and Development, 80(2), 204-214. doi:10.1002/j.1556-6678.2002.tb00184.x 
Hair, J., Anderson, R., Tatham, R., \& Black, W. (2006). Multivariate Data Analysis. New Jersey, NJ: Pearson/Prentice Hall.

Hemphill, J. F. (2003). Interpreting the magnitudes of correlation coefficients. American Psychologist, 58(1), 78-79. doi:10.1037/0003-066X.58.1.78

Hiott, D. W., \& Labbate, L. (2002). Anxiety disorders associated with traumatic brain injuries. Neuro Rehabilitation, 17(4), 345-355.

Hodgson, J., McDonald, S., Tate, R., \& Gertler, P. (2012). A Randomised Controlled Trial of a Cognitive-Behavioural Therapy Program for Managing Social Anxiety After Acquired Brain Injury. Brain Impairment, 6(3), 169-180. doi:10.1375/brim.2005.6.3.169

Horton, N. J., Lipsitz, S. R., \& Parzen, M. (2003). A potential for bias when rounding in multiple imputation. The American Statistician, 57(4), 229-232. doi:10.1198/0003130032314

Jones, J., Haslam, A., Jetten, J., Williams, H., Morris, R., \& Saroyan, S. (2010). That which doesn't kill us can make us stronger (and more satisfied with life): The contribution of personal and social changes to well-being after acquired brain injury. Psychology \& Health, 26(3), 353369. doi: $10.1080 / 08870440903440699$

Jones, J., Williams, H., Jetten, J., Haslam, A., Harris, A., \& Gleibs, I.H. (2012). The role of psychological symptoms and social group memberships in the development of post-traumatic stress after traumatic injury. British Journal of Health Psychology, 17(4), 798-811. doi:10.1111/j.2044-8287.2012.02074.x

Kelly, D. F., \& Becker, D. P. (2001). Advances in management of neurosurgical trauma: USA and Canada. World Journal of Surgery, 25(9), 1179-1185. doi: 10.1007/s00268-001-0080-x

Kendall, E., \& Terry, D. (1996). Psychosocial adjustment following closed head injury: A model for understanding individual differences and predicting outcome. Neuropsychological Rehabilitation, 6(2), 101-132. doi:10.1080/713755502 
Kennedy, B. L., Lynch, G. V., \& Schwab, J. J. (1998). Assessment of locus of control in patients with anxiety and depressive disorders. Journal of Clinical Psychology, 54(4), 509-515. doi:10.1002/(SICI)1097-4679(199806)54:4

Kervick, R. B., \& Kaemingk, K. L. (2005). Cognitive appraisal accuracy moderates the relationship between injury severity and psychosocial outcomes in traumatic brain injury. Brain Injury, 19(11), 881-889. doi:10.1080/02699050400025273

Kessler, R. C., Berglund, P., Demler, O., Jin, R., Merikangas, K. R., \& Walters, E. E. (2005). Lifetime Prevalence and Age-of-Onset Distributions of DSM-IV Disorders in the National Comorbidity Survey Replication. Archives of General Psychiatry, 62(6), 593. doi:10.1001/archpsyc.62.6.593

Kim, E., Lauterbach, E.C., Reeve, A., Arciniegas, D.B., Coburn, K.L., Mendez, M.F., ... Coffey, E.C. (2007). Neuropsychiatric complications of traumatic brain injury: a critical review of the literature (a report by the ANPA Committee on Research). Journal of Neuropsychiatry and Clinical Neuroscience, 19(2), 106-127. doi: 10.1176/jnp.2007.19.2.106

Kolb, B., \& Whishaw, I.Q. (2003). Fundamentals of human neuropsychology (5 $5^{\text {th }}$ ed.). New York, NY: Worth Publishers.

Konrad, C., Geburek, A.J., Rist, F., Blumenroth, H., Fischer, B., Husstedt, I., ...Lohmann, H. (2010). Long-term cognitive and emotional consequences of mild traumatic brain injury. Psychological Medicine, 41(6), 1197-211. doi:10.1017/S0033291710001728

Leary, M. R., \& Atherton, S. C. (1986). Self-efficacy, social anxiety, and inhibition in interpersonal encounters. Journal of Social and Clinical Psychology, 4(3), 256-267. doi:10.1521/jscp.1986.4.3.256

Leary, M. R., \& Baumeister, R. F. (2000). The nature and function of self-esteem: Sociometer theory. In M. P. Zanna (Eds.), Advances in Experimental Social Psychology, 32, 1-62. doi:10.1016/S0065-2601(00)80003-9 
Levack, W.M., Kayes, N.M., Fadyl, J. K. (2010). Experience of recovery and outcome following traumatic brain injury: A metasynthesis of qualitative research. Disability and Rehabilitation, 32(12), 986-999. doi: 10:3109/09638281003775394

Linden, M. A., \& Boylan, A. M. (2010). 'To be accepted as normal': Public understanding and misconceptions concerning survivors of brain injury. Brain Injury, 24(4), 642-650. doi:10.3109/02699051003601689

Little, R. J. (1988). A test of missing completely at random for multivariate data with missing values. Journal of the American Statistical Association, 83(404), 1198-1202. doi:10.1080/01621459.1988.10478722

Mattson, A., \& Levin, H. (1990). Frontal lobe dysfunction following closed head injury. A review of the literature. The Journal of Nervous and Mental Disease, 178(5). doi:10.1097/00005053199005000-00002

McClure, J. (2011). The role of causal attributions in public misconceptions about brain injury. Rehabilitation Psychology, 56(2), 85-93. doi:10.1037/a0023354

McDowell, R. D., Ryan, A., Bunting, B. P., O'Neill, S. M., Alonso, J., Bruffaerts, R. ... Tomov, T. (2013). Mood and anxiety disorders across the adult lifespan: A European perspective. Psychological Medicine, 44(4), 707-722. doi:10.1017/S0033291713001116

Menard, S. (1995). Applied logistic regression analysis. California, CA: Sage.

Menon, D. K., Schwab, K., Wright, D. W., \& Maas, A. I. (2010). Position Statement: Definition of Traumatic Brain Injury. Archives of Physical Medicine and Rehabilitation, 91(11), 16371640. doi:10.1016/j.apmr.2010.05.017

Moore, A. D., \& Stambrook, M. (1992). Coping strategies and locus of control following traumatic brain injury: relationship to long-term outcome. Brain Injury, 6(1), 89-94. doi: $10.3109 / 02699059209008129$ 
Moore, Terryberry-Spohr, L., \& Hope, D. A. (2006). Mild traumatic brain injury and anxiety sequelae: A review of the literature. Brain Injury, 20(2), 117-132. doi:10.1080/02699050500443558

Morris, P. G., Prior, L., Deb, S., Lewis, G., Mayle, W., Burrow, C. E., \& Bryant, E. (2005). Patients' views on outcome following head injury: A qualitative study. BMC Family Practice, 6(1), 30. doi: 10.1186/1471-2296-6-30

Morton, M. V., \& Wehman, P. (1995). Psychosocial and emotional sequelae of individuals with traumatic brain injury: a literature review and recommendations. Brain Injury, 9(1), 81-92. doi:10.3109/02699059509004574

National Institute for Health and Care Excellence. (2013). Social Anxiety Disorder: The NICE Guideline on Recognition, Assessment and Treatment. Retrieved from http://www.nice.org.uk/nicemedia/live/14168/63846/63846.pdf

National Institute for Health and Care Excellence. (2014). Head injury: Triage, assessment, investigation and early management of head injury in children, young people and adults. Retrieved from https://www.nice.org.uk/guidance/cg176/

Neuro-QOL (2010). Neuro-QOL report: Item Bank Development and Item Response Theory Statistics. Retrieved from http://www.neuroqol.org/Resources/Resources\%20documents/Neuro-QOL-Tech\%20Rept2013.pdf/

Neuro-QOL (2012). Adult item banks. Accessed online at http://www.neuroqol.org/WhatandWhy/ItemBanks/Adults\%20Item\%20BAnks/Pages/default. aspx/

Newton, A., \& Johnson, D. A. (1985). Social adjustment and interaction after severe head injury. The British Journal of Clinical Psychology, 24(4), 225-234. doi:10.1111/j.20448260.1985.tb00655.x 
Nochi, M. (1998). "Loss of self" in the narratives of people with traumatic brain injuries: A qualitative analysis. Social Science \& Medicine, 46(7), 869-878. doi:10.1016/S02779536(97)00211-6

Ohayon, M.M., Schatzberg, A.F. (2010). Social phobia and depression: prevalence and comorbidity. Journal of Psychosomatic Research, 68(3), 235-243. doi: 10.1016/j.jpsychores.2009.07.018.

Oliver, M. (1983). Social Work with Disabled People. Basingstoke, England: Macmillan.

Oliver, M. (2004). The social model in action: If I had a hammer. In C. Barnes, G. Mercer (Eds.), Implementing the social model of disability: theory and research (pp. 18-31). Leeds, England: The Disability Press.

Osborn, A.J., Mathias, J.L., \& Fairweather-Schmidt, A.K. (2014). Depression following adult, nonpenetrating traumatic brain injury: A meta-analysis examining methodological variables and sample characteristics. Neuroscience \& Biobehavioral Reviews, 47, 1-15. doi:10.1016/j.neubiorev.2014.07.007

Ownsworth, T. (2014). Self-identity after brain injury. New York, NY: Psychology Press.

Pierce, C. A., \& Hanks, R. A. (2006). Life Satisfaction After Traumatic Brain Injury and the World Health Organization Model of Disability. American Journal of Physical Medicine \& Rehabilitation, 85(11). doi:10.1097/01.phm.0000242615.43129.ae

Poder, K., Ghatavi, K., Fisk, J. D., Campbell, T. L., Kisely, S., Sarty, I., ... Bhan, V. (2009). Social anxiety in a multiple sclerosis clinic population. Multiple Sclerosis, 15(3), 393-398. doi: $10.1177 / 1352458508099143$

Ponsford, J.L., Downing, M., Olver, J., Ponsford, M., Acher, R., Carty, M., \& Spitz, G. (2014). Longitudinal Follow-Up of Patients with Traumatic Brain Injury: Outcome at Two, Five, and Ten Years Post-Injury. Journal of Neurotrauma, 31(1), 64-77. doi: 10.1089/neu.2013.2997 
Ponsford, J., Kelly, A., \& Couchman, G. (2014). Self-concept and self-esteem after acquired brain injury: A control group comparison. Brain Injury, 28(2), 146-154. doi:10.3109/02699052.2013.859733

Qualtrics (2013). Qualtrics Survey Software. [Software]. Available from http://www.qualtrics.com/ Rao, D., Choi, S. W., Victorson, D., Bode, R., Peterman, A., Heinemann, A., \& Cella, D. (2009). Measuring stigma across neurological conditions: the development of the stigma scale for chronic illness (SSCI). Quality of Life Research, 18(5), 585-595. doi:10.1007/s11136-009$9475-1$

Rao, V., \& Lyketsos, C. G. (2002). Psychiatric aspects of traumatic brain injury. Psychiatric Clinics of North America, 25(1), 43-69. doi:10.1016/s0193-953x(03)00052-2

Rapee, R. M., \& Spence, S. H. (2004). The etiology of social phobia: Empirical evidence and an initial model. Clinical Psychology Review, 24(7), 737-767. doi:10.1016/j.cpr.2004.06.004

Reeve, D. (2012). Psycho-emotional disablism: the missing link? In N. Watson, A. Roulstone, \& C. Thomas (Eds.), Routledge Handbook of Disability Studies (pp. 78-93). London, England: Routledge.

Ritter, V., Ertel, C., Beil, K., Steffens, M. C., \& Stangier, U. (2013). In the Presence of Social Threat: Implicit and explicit self-esteem in social anxiety disorder. Cognitive Therapy and Research, 37(6), 1101-1109. doi:10.1007/s10608-013-9553-0

Rochat, L., Ammann, J., Mayer, E., Annoni, J.M., \& Van Der Linden, M. (2009). Executive disorders and perceived socio-emotional changes after traumatic brain injury. Journal of Neuropsychology, 3(2), 213-227. doi:10.1348/174866408X397656

Rosenberg, M. (1965). Society and the adolescent self-image. New Jersey, NJ: Princeton. Rosenberg, M. (1979). Conceiving the Self. New York, NY: Basic Books.

Rubin, D.B. (1987). Multiple Imputation for Nonresponse in Surveys. New York: Wiley.

Schafer, J.L. (1997) Analysis of Incomplete Multivariate Data. London, England: Chapman \& Hall. 
Scheutzow, M. H., \& Wiercisiewski, D. R. (1999). Panic disorder in a patient with traumatic brain injury: A case report and discussion. Brain Injury, 13(9), 705-714. doi: $10.1080 / 026990599121250$

Scholten, A.C., Haagsma, J.A., Cnossen, M.C., Olff, M., Van Beeck, E.F., \& Polinder, S. (2016). Journal of Neurotrauma, ahead of print. doi:10.1089/neu.2015.4252.

Simpson, J., McMillan, H., \& Reeve, D. (2013). Reformulating Psychological Difficulties in People with Parkinson's Disease: The Potential of a Social Relational Approach to Disablism. Parkinson's Disease, 2013(3), 1-8. doi:10.1002/mds.23462

Simpson, J., \& Thomas, C. (2014). Clinical psychology and disability studies: bridging the disciplinary divide on mental health and disability. Disability and Rehabilitation, 1-6. doi:10.3109/09638288.2014.961656

Sohlberg, M. M., \& Mateer, C. A. (2001). Cognitive rehabilitation: An integrative neuropsychological approach. New York, NY: Guilford Press.

Soo, C., \& Tate, R.L. (2009). Psychological treatment for anxiety in people with traumatic brain injury. Cochrane Database of Systematic Reviews, 3, 1-23. doi:10.1002/14651858.CD005239.pub2.

Soo, C., Tate, R. L., \& Rapee, R. M. (2012). Social anxiety and its treatment in children and adolescents with acquired brain injury. In V. Anderson \& M. Beauchamp (Eds.), Developmental social neuroscience and childhood brain insult: Theory and practice (pp. 370-388). New York, NY: Guildford.

Tate, R. L., \& Broe, G. A. (1999). Psychosocial adjustment after traumatic brain injury: What are the important variables? Psychological Medicine, 29(3), 1-13. doi:10.1017/S0033291799008466

Temkin, N. R., Corrigan, J. D., Dikmen, S. S., \& Machamer, J. (2009). Social functioning after traumatic brain injury. The Journal of Head Trauma Rehabilitation, 24(6), 460-467. doi:10.1097/htr.0b013e3181c13413 
Truelle, J. L., Fayol, P., Montreuil, M., \& Chevignard, M. (2010). Community integration after severe traumatic brain injury in adults. Current Opinion in Neurology, 23(6), 688-694. doi:10.1097/WCO.0b013e3283404258

Waldron, B., Benson, C., O' Connell, A., Byrne, P., Dooley, B., \& Burke, T. (2010). Health locus of control and attributions of cause and blame in adjustment to spinal cord injury. Spinal Cord, 48(8), 598-602. doi:10.1038/sc.2009.182

Wallston, K. A. (2005). The Validity of the Multidimensional Health Locus of Control Scales. Journal of Health Psychology, 10(5), 623-631. doi:10.1177/1359105305055304

Wallston, K. A., Stein, M. J., \& Smith, C. A. (1994). Form C of the MHLC scales: A ConditionSpecific Measure of Locus of Control. Journal of Personality Assessment, 63(3), 534-553. doi:10.1207/s15327752jpa6303_10

Wells, A. (2013). Cognitive Therapy of Anxiety Disorders. Chichester, England: John Wiley \& Sons. Whelan-Goodinson, R., Ponsford, J., \& Schönberger, M. (2009). Validity of the Hospital Anxiety and Depression Scale to assess depression and anxiety following traumatic brain injury as compared with the Structured Clinical Interview for DSM-IV. Journal of Affective Disorders, 114(3), 94-102. doi:10.1016/j.jad.2008.06.007

Whelan-Goodinson, R., Ponsford, J.L., Schönberger, M., \& Johnston, L. (2010). Predictors of psychiatric disorders following traumatic brain injury. Journal of Head Trauma Rehabilitation, 25(5), 320-9. doi:10.1097/HTR.0b013e3181c8f8e7

Williams, W. H., Evans, J. J., \& Fleminger, S. (2003). Neurorehabilitation and cognitive-behaviour therapy of anxiety disorders after brain injury: An overview and a case illustration of obsessive-compulsive disorder. Neuropsychological Rehabilitation, 13(1-2), 133-148. doi: $10.1080 / 09602010244000417$ 
Wilson, B. A. \& Gracey, F. (2009). Towards a comprehensive model of neuropsychological rehabilitation. In B. A. Wilson (Eds.), Neuropsychological rehabilitation: Theory, models, therapy and outcome. New York: Cambridge University Press.

World Health Organisation (2006). Neurological disorders: Public health challenges. Retrieved from http://www.who.int/mental_health/publications/neurological_disorders_ph_challenges/en/

Wright, J. C., \& Telford, R. (1996). Psychological problems following minor head injury: a prospective study. The British Journal of Clinical Psychology, 35(3), 399-412. doi:10.1111/j.2044-8260.1996.tb01194.x

Yeates, G. N., Gracey, F., \& Mcgrath, J. C. (2008). A biopsychosocial deconstruction of "personality change" following acquired brain injury. Neuropsychological Rehabilitation, 18(5-6), 566589. doi:10.1080/09602010802151532

Zigmond, A. S., \& Snaith, R. P. (1983). The hospital anxiety and depression scale. Acta Psychiatrica Scandinavica, 67(6), 361-370. doi:10.1111/j.1600-0447.1983.tb09716.x 
Dr William Curvis, Lancaster University, Lancaster, UK.

Dr Jane Simpson, Lancaster University, Lancaster, UK.

Dr Natalie Hampson, Salford Royal NHS Foundation Trust, Salford, UK.

Abstract word count: 185

Word count (excluding abstract, references, appendices \& tables): 6940

Correspondence should be addressed to:

Dr William Curvis, Doctorate in Clinical Psychology, Division of Health Research, Floor C, Furness College, Lancaster University, Lancaster L1 4YG.

E-mail: wcurvis@gmail.com 


\begin{abstract}
Social anxiety (SA) following traumatic brain injury (TBI) has the potential to affect an individual's general psychological wellbeing and social functioning, however little research has explored factors associated with its development. The present study used hierarchical multiple regression to investigate the demographic, clinical and psychological factors associated with SA following TBI. A sample of 85 people who experienced TBI were recruited through social media websites and brain injury services across the NorthWest of England. The overall combined biopsychosocial model was significant, explaining 52-54.3\% of the variance in SA (across five imputations of missing data). The addition of psychological variables (self-esteem, locus of control, self-efficacy) made a significant contribution to the overall model, accounting for an additional $12.2-13 \%$ of variance in SA above that explained by demographic and clinical variables. Perceived stigma was the only significant independent predictor of SA $(B=.274, p=.005)$. The findings suggest that psychological variables are important in the development of SA following TBI and must be considered alongside clinical factors. Furthermore, the significant role of stigma highlights the need for intervention at both an individualised and societal level.
\end{abstract}

Keywords: traumatic brain injury, social anxiety, stigma, psychological 
Social Anxiety Following Traumatic Brain Injury: An Exploration of Associated Factors Traumatic brain injury (TBI), generally defined as a non-degenerative insult to the brain caused by an external mechanical force (e.g., from a road traffic accident or a fall), can lead to temporary or permanent impairment of brain function, affecting cognitive and physical abilities (World Health Organisation [WHO], 2006; Menon, Schwab, Wright, \& Maas, 2010). Head injuries are the most common cause of death and impairment in people under 40 (National Institute for Health and Care Excellence [NICE], 2014; WHO, 2006).

People who have experienced a traumatic brain injury (TBI) are at increased risk of developing psychological difficulties such as depression and anxiety (Scholten et al., 2016; Osborn, Mathias, \& Fairweather-Schmidt, 2014; Gould, Ponsford, Johnston and Schönberger, 2011; Whelan-Goodinson, Ponsford, Schönberger \& Johnston, 2010; Bryant et al., 2010). However, recognising psychological problems after TBI can be challenging, given the complex interactions between the neurological and emotional sequelae of TBI and the difficulties in identifying symptoms of psychological problems in the context of other factors (e.g., cognitive impairment, physical disability) associated with TBI (Kim et al., 2007; Scheutzow \& Wiercisiewski, 1999). Nonetheless, as psychological problems following TBI can be longstanding (Konrad et al., 2011) and may affect wellbeing and inhibit recovery (Osborn et al., 2014), it is imperative to improve understanding and management of these difficulties during assessment and rehabilitation (Williams, Evans \& Fleminger, 2003).

Furthermore, it is vital to understand the social context in which TBI rehabilitation occurs. Social functioning is commonly affected by TBI and this can have a significant impact on life satisfaction (Pierce \& Hanks, 2006; Truelle, Fayol, Montreuil, \& Chevignard, 2010; Jones et al., 2010). Qualitative research highlights the importance of social activity following TBI in making sense of oneself (Yeates, Gracey, \& Mcgrath, 2008), and social support is predictive of lower levels of post-traumatic stress (Jones et al., 2012). However, 
declines in activity, social contact, independence, functional status and employment opportunities are often reported following TBI (Antonak, Livneh, \& Antonak, 1993; Temkin, Corrigan, Dikmen, \& Machamer, 2009). Severity of injury fails to account fully for differences in psychosocial functioning (Antonak et al., 1993) and life satisfaction post-TBI (Jones et al., 2010), with the latter study finding that social support mediated the relationship between well-being and injury severity.

Moreover, following TBI people may feel embarrassed or self-conscious in social situations given the frequency of physical consequences (e.g., physical impairment, hemiparesis, skull depressions, scarring, tremors, motor/speech problems) and often unseen cognitive problems with word finding, attention, memory, executive functioning and processing speed (Rochat, Ammann, Mayer, Annoni, Van Der Linden, 2009; Hiott \& Labbate, 2002; Moore, Terryberry-Spohr \& Hope, 2006). Therefore, social interaction can be negatively impacted following TBI if a person is less able to follow or engage in conversation (Morris et al., 2005). Consequently, problems following TBI may result in people becoming particularly anxious in social situations (Moore et al., 2006; Wright \& Telford, 1996).

However, despite the importance of social reintegration, social anxiety in people with a TBI has been the subject of very little research. Social anxiety (SA) is characterised by a marked fear of situations in which a person might face scrutiny from others and subsequent avoidance of common triggers (e.g., social interactions, meeting new people, public speaking) which can result in significant distress and impairments in functioning (National Institute for Health and Care Excellence [NICE], 2013; American Psychiatric Association [APA], 2013). While both anxiety (Rao \& Lyketsos, 2002) and declines in psychosocial functioning (Ponsford et al., 2014; Antonak et al., 1993) following TBI are well documented, the available research examining SA following TBI is limited and of poor quality. Only two studies have been identified which have assessed social anxiety in this population. A 
prospective cohort study of people who had experienced traumatic injuries found that $6.1 \%$ of people with mild-TBI met criteria for SA three months post-injury, rising to $9 \%$ after 12 months (Bryant et al., 2010). Conversely, Newton and Johnson (1985) found that SA was lower in participants with a TBI compared to those without. However, the TBI group comprised only eleven participants who exhibited a broad range of scores on a measure of SA. The authors concluded that although the mean score was lower than the control group, a high level of SA was observed in the majority of the TBI group $(n=8)$.

This lack of research interest may be a consequence of the complex interaction and overlap between psychological and neurological problems as discussed above. It may also result from the criteria within the Diagnostic and Statistical Manual of Mental Disorders, Fifth Edition (DSM-5; APA, 2013) for SA which state that, if a medical condition is present, anxiety or avoidance must be unrelated or out of proportion to it. This suggests that a diagnostic label of social anxiety disorder may not be appropriate for people experiencing anxiety in social situations after TBI. This may result in social anxiety not being considered in this population, or such difficulties being attributed to the cognitive or neurological consequences of TBI. However, this is not in keeping with recommendations for a broad and biopsychosocial approach to providing support and rehabilitation following TBI (Gracey, Evans \& Malley, 2009; Wilson \& Gracey, 2009).

No guidance is available specific to the management of SA after TBI, but empiricallybased guidance for generic SA interventions in the UK (NICE, 2013) recommends cognitive behavioural therapy (CBT) as a first-line intervention (i.e., before pharmacological interventions), underpinned by a specifically developed theoretical model (e.g., Clark \& Wells, 1995). However, a randomised controlled trial of a CBT programme for SA after acquired brain injury $(\mathrm{ABI})$ found that although SA did reduce, treatment effects were not statistically significant (Hodgson, McDonald, Tate, \& Gertler, 2012). However, a small 
sample size $(n=12)$ and variability in the ABI group (people who had experienced stroke, hypoxic brain injury and cerebral oedema were included alongside those who had experienced TBI) limits the usefulness of this study in understanding management of SA after TBI.

Despite the lack of research or guidance around SA after TBI, a literature review exploring anxiety following mild TBI (Moore et al., 2006) highlighted the potential for SA to be a significant problem in this population. Furthermore, Soo, Tate and Rapee (2012) present a theoretical rationale for high levels of SA in children and adolescents who have experienced TBI. They draw on Kendall and Terry's (1996) model for understanding individual differences and predicting psychosocial adjustment outcomes following TBI, acknowledging a role for direct (neurological and cognitive impairment) and indirect (situational and environmental) antecedent factors, but also emphasising the importance of an individual's psychological resources such as appraisal style and coping responses. This is consistent with cognitive theories of SA (e.g., Clark \& Wells, 1995; Wells, 2013) and approaches to management of other anxiety problems following TBI (Williams et al., 2003; Soo \& Tate, 2009). Consequently, an understanding of SA following TBI in adults must be guided by research which explores the role of potentially relevant neurological, cognitive, situational and psychological factors to guide assessment, formulation and intervention during acute and long-term rehabilitation.

A broad range of psychological variables may be important in SA following TBI (Soo et al., 2012). Locus of control (LoC), the beliefs a person holds about how the behaviour of themselves and others influences their health (Wallston, Stein, \& Smith, 1994), has been associated with SA (Cloitre, Heimberg, Liebowitz, \& Gitow, 1992; Kennedy, Lynch, \& Schwab, 1998) and emotional problems in people who have experienced TBI (Moore \& Stambrook, 1992). Self-efficacy, the beliefs people hold about their capabilities is also 
associated with SA (Leary \& Atherton, 1986) and is predictive of global life satisfaction following TBI (Cicerone \& Azulay, 2007). Low self-esteem is also linked to SA (Ritter, Ertel, Beil, Steffens, \& Stangier, 2013). Though debate continues around the consistency of the construct, self-esteem is generally defined as the global, subjective and emotional judgements one holds about the self (Guindon, 2002), which are activated and reinforced in social situations and contribute to fear of negative evaluation (Wells, 2013; Clark \& Wells, 1995; Rapee \& Spence, 2004). People who have experienced TBI have been found to have lower self-esteem (Ponsford, Kelly, \& Couchman, 2014) and self-esteem has been shown to predict psychosocial outcomes following TBI (Tate \& Broe, 1999).

Furthermore, fear of negative evaluation may mean that people with SA perceive or experience higher levels of stigma (Anderson, Jeon, Blenner, Wiener, \& Hope, 2015; Clark \& Wells, 1995). People who are socially anxious may be rejected or perceived negatively, particularly if anxiety related behaviours (e.g., gripping hands together, avoiding eye contact) compound the anxiety symptoms or impair social performance (Wells, 2013; Rapee \& Spence, 2004). As highlighted above, the physical and cognitive consequences of TBI may add further challenges to social interactions. Qualitative research has suggested stigma may be a potential factor affecting wellbeing following TBI, with participants highlighting the lack of public understanding about the consequences of TBI and how this impacts on their social engagement (Morris et al., 2005; Nochi, 1998). Furthermore, perceived stigma is strongly associated with anxiety in people with chronic physical conditions (Alonso et al., 2008) and epilepsy (Beyenburg, Mitchell, Schmidt, Elger, \& Reuber, 2005).

In conclusion, despite the theoretical rationale for SA following TBI presented by Soo et al. (2012) and Moore et al., (2006), present understanding of SA following TBI is limited given the limited available research. No research to date has explored psychological factors which might contribute to the development of SA following TBI to provide guidance for 
assessment and intervention. While it is recognised that psychological problems may predate a brain injury (Williams et al., 2003), people who have experienced TBI may be at greater risk of developing SA due to the nature of the factors described above. Consequently, the present study aimed to investigate psychological factors associated with SA following TBI, alongside clinical and demographic variables. It was hypothesised that psychological variables such as LoC, self-efficacy, self-esteem and perceived stigma would account for an additional and significant amount of variance in SA, above that explained by demographic and clinical variables.

\section{Methods}

\section{Design}

The study employed a quantitative, cross-sectional within-subjects design to explore factors predicting SA after TBI. Self-report questionnaires were used as the data collection method. If required, participants were given support from the lead researcher to complete the questionnaires.

\section{Participants}

Participants were required to have sustained a TBI, defined as an injury caused by an external or mechanical force (Morton \& Wehman, 1995), to differentiate from the broader categorisation of ABI. Participants in the study were required to be aged over 18 and able to read English (due to lack of the validated measures in other languages).. As the research literature regarding the developmental impact of TBI in childhood is scarce (Barlow, Thompson, Johnsen, \& Minns, 2004), participants-Participants were required to have sustained a TBI after the age of 16 to allow for specific examination of factors in relation to adults, as other developmental factors are likely to influence cognitive and psychological outcomes following TBI experienced in childhood or adolescence (Anderson et al., 2006; Catroppa, Anderson, Morse, Hariou, \& Rosenfeld, 
2008). Given the focus on social functioning, participants were required to be living in the community (either at home or in long-term supported accommodation) rather than a medical ward or residential rehabilitation unit. Participants were also required to have capacity to consent to participation in the study.

An a priori power calculation for multiple regression analysis, assuming a medium effect size of $0.15,80 \%$ power and an alpha level set at $p=.05$, suggested that a sample of between 92 and 139 would be required. A total of 98 participants were recruited, with 54 participants completing the questionnaires online and 44 submitting paper copies provided via National Health Service (NHS) or third sector services. Five participants who completed the study online were excluded from the analysis as they described their injury as an ABI (e.g., subarachnoid haemorrhage) rather than a TBI and therefore did not meet all the inclusion criteria. A further eight participants were excluded as a significant amount of questionnaire data (more than 10\%, as recommended by Bennett, 2001) were missing.

Therefore, a total of 85 participants provided data for the analyses. Participants ranged in age from 19 to 81 years $(M=42.4, S D=13.335)$. The final sample included $63.5 \%$ $(n=54)$ males and $32.9 \%(n=28)$ females, with $3.5 \%(n=3)$ reporting "Other / Prefer not to say". Further demographic information is shown in Table 1.

\section{[INSERT TABLE 1 HERE]}

Due to ethical and resource constraints, medical data regarding severity of injury were not available. Participants were asked to report the length of time they were in hospital for after their injury $(M=16.529$ weeks, $S D=32.120)$ and time since injury $(M=7.719$ years, $S D=8.733)$

\section{Measures}

Outcome variable. The Social Phobia Inventory (SPIN; Connor et al., 2000) was used as the outcome measure for the study. The SPIN is a 17-item self-report measure of 
three domains of SA; fear, avoidance and physiological discomfort. Responses are scored from 0 (not at all) to 4 (extremely), with a maximum total score of 68 indicating high levels of SA. A cut-off score of 19 is recommended by the authors to distinguish those with SA. High levels of internal consistency $(\alpha=.95)$ and test-retest reliability $(r=.86)$ have been demonstrated (Antony, Coons, McCabe, Ashbaugh, \& Swinson, 2006; Connor et al., 2000). Although the measure has not been used in a TBI population in any published research to date, it has been utilised with patients with multiple sclerosis (Poder et al., 2009) and is recommended by guidance provided by NICE (2013) for use in NHS services within the UK. The SPIN's face validity and brevity make it the most appropriate measure from available measures of SA.

Predictor variables. The Applied Cognition measure (Neuro-QOL, 2012) was used to assess subjective severity of cognitive problems. This 18 -item measure assesses perceived difficulties in everyday cognitive domains including memory, attention, and decisionmaking. Responses range from never (1) to very often (5), with a maximum score of 90. High levels of internal consistency $(\alpha=.95)$ and test-retest reliability $(r=.82)$ have been demonstrated in samples of patients with a range of neurological problems (e.g., stroke, epilepsy, Parkinson's disease) but data are not available for a TBI sample (Neuro-QOL, 2010).

Form C of the Multidimensional Health Locus of Control (MHLoC, Wallston, Stein, \& Smith, 1994) assesses belief in one's ability to control health outcomes, in relation to a specific illness or disease. The measure encompasses four subscales of LoC: internal; chance; powerful others (doctors) and powerful others (other people). Responses are scored from 1 (strongly disagree) to 6 (strongly agree), with a higher subscale score indicating higher LoC (no total score is calculated). Wallston et al. (1994) demonstrated acceptable levels of internal consistency and test-retest reliability for each subscale; internal $(\alpha=.79-.87 ; r=.80)$, 
chance $(\alpha=.79-.82 ; r=.72)$, doctors $(\alpha=.71 ; r=.58)$ and other people $(\alpha=.70-.71 ; r=$ .40). Despite its focus on control over one's specific illness or disease (Wallston, 2005), no published research has used Form $\mathrm{C}$ with a TBI population. However, Forms A and B of the MHLoC have been used in previous TBI research (Bedard et al., 2005; Moore \& Stambrook, 1992), and Form $\mathrm{C}$ has been used to assess LoC following spinal cord injury (Waldron et al., 2010).

The Rosenberg Self-Esteem Scale (RSES, 1965) is a 10-item measure, with responses recorded on a 0 to 3 scale (reverse coded on some items) so that a low score on the RSES indicates low self-esteem. The RSE demonstrates high internal consistency ( $\alpha=.92)$, and test-retest reliability $(r=.85)$ after two weeks (Rosenberg, 1979). This measure has been used to examine self-esteem in people who have experienced a TBI (e.g., Anson \& Ponsford, 2006a; Anson \& Ponsford, 2006b; Ponsford et al., 2014).

The Self-Efficacy for Symptom Management Scale (Cicerone \& Azulay, 2007) assesses confidence in managing common challenges and seeking support after TBI. The 13items measure is scored 1 (not at all confident) to 10 (totally confident), with a maximum total score of 130 indicating high self-efficacy. High levels of internal consistency $(\alpha=.93)$ and test-retest reliability $(r=.93)$ have been demonstrated (Cicerone \& Azulay, 2007). The Stigma scale published by Neuro-QOL (2012) is a 24-item measure which examines a person's perceptions of self and publically enacted prejudice and discrimination experienced as a result of neurological problems. Responses are scored from 1 (never) to 5 (always), with a maximum score of 120 indicating high levels of perceived stigma. High levels of internal reliability $(\alpha=.91)$ and test-retest reliability $(r=.82)$ have been demonstrated in samples of patients with a range of neurological problems (e.g., stroke, epilepsy, Parkinson's disease) but no data are available for a TBI sample (Rao et al., 2009). 
For the purposes of the study, the word 'illness' was replaced with the term 'brain injury' on each item of the questionnaire.

The Hospital Anxiety and Depression Scale (HADS; Zigmond \& Snaith, 1983) was designed for use with people with physical health problems and assesses anxiety and depression without relying on somatic symptoms of illness (e.g., fatigue, insomnia). The 14item measure is scored on a 0 to 3 scale, appropriately coded so that a higher score on each subscale indicates a more severe problem with anxiety or depression. A review of its psychometric properties reports good levels of internal consistency on the anxiety $(\alpha=.68$ $.93)$ and depression $(\alpha=.67-.9)$ subscales across a variety of settings (Bjelland, Dahl, Haug, \& Neckelmann, 2002), with similar findings reported by Whelan-Goodinson, Ponsford and Schönberger (2009) with a TBI sample (depression $\alpha=.88$; anxiety $\alpha=.92$ ). The HADS has been used to measure depression and anxiety after TBI in a number of published studies (e.g., Anson \& Ponsford, 2006a; Anson \& Ponsford, 2006b; Downing, Stolwyk, \& Ponsford, 2013).

\section{Procedure}

Potential participants were identified and recruited through professionals working in neuropsychology teams across nine NHS Trusts in the North-West of England and third sector organisations relevant to TBI. Participants were also able to self-refer into the study and could opt to complete an online version of the study made using Qualtrics Survey Software (Qualtrics, 2013), which provided security and encryption for online information. The study was advertised via social networking websites and posters displayed in NHS neuropsychology services and third sector organisations.

Prior to completing the questionnaires, participants were required to complete a screening and consent form based on the inclusion and exclusion criteria outlined above. On the online version of the study, participants were only able to progress onto the 
questionnaires if they answered each item of the consent form. Capacity to consent and participate in the study was assumed in line with the UK Mental Capacity Act (2005).

Participants had the option of completing the questionnaires online or on paper posting them to the lead researcher. To reduce bias, the online study was set to present questionnaires in a random order.

\section{Ethical Approval}

The study received ethical approval from the UK NHS National Research Ethics Service, followed by local approval from the Research and Development Departments of each NHS Trust involved in recruitment. This approval also covered participants recruited through third sector organisations and online.

\section{Data Analysis Strategy}

Data were analysed using IBM SPSS Statistics version 20. All questionnaires were scored in accordance with scale instructions and reverse coded as required. Relationship status was recoded to a binary variable (i.e., yes / no). Due to its descriptive nature, cause of injury was not entered into the regression model. Anxiety (measured by HADS) was not entered into the regression model as it correlated too highly with the outcome variable $(r=$ $.726, p<.001)$ and, as it is conceptually similar, would have reduced the variance available to other variables. Additionally, depression was considered a clinical variable rather than a psychological one, due to the focus of the HADS on measuring clinical difficulties associated with depression.

Throughout the study, a $p$ value of .05 was used as a threshold for statistical significance in line with convention (Field, 2013). Furthermore, the decision was taken not to use Bonferroni corrections to counteract multiple comparisons as this would have resulted in a very low $p$ value and significantly reduced statistical power. 
Hierarchical multiple regression analysis was used to explore the study hypothesis. Variables were entered into the model in three blocks; demographic, clinical, psychological. Consistent with the available theoretical rationale for SA following TBI discussed above, this allowed for examination of the amount of variance in SA which could be explained by psychological variables, above that explained by demographic and clinical variables.

In determining what variables were entered into the regression model, decisions for subset selection were made based on effect size instead of $p$ values. While use of $p$ values is common, effect sizes are less reliant on sample size (Coe, 2002). Given the relatively low sample size in this study $(n=85)$, variables were included in the multiple regression analysis if a small effect size was observed (i.e., $r>.1$; Cohen, 1988). This threshold was chosen to allow an inclusive, exploratory approach which minimised the risk of overlooking emerging effects of small magnitude (Hemphill, 2003).

\section{Results}

\section{Data Preparation and Analysis}

It did not appear that there were any systematic biases or patterns to the missing data as defined by Graham (2009), with 34 cases (40\% of the sample) having incomplete data across 42 (34.43\%) of the variables. Little's (1988) Missing Completely At Random (MCAR) test was not significant $\left(X^{2}=1921.880, d f=3105, p=1.000\right)$, suggesting that the null hypothesis of data being missing randomly could be assumed.

Even after removing the eight cases missing more than $10 \%$ of data, the number of other cases missing smaller amounts of data was high. Listwise or pairwise deletion methods were not considered appropriate as this would have seen a large proportion of cases deleted, thereby reducing sample size and power in addition to potentially introducing bias into the multiple regression model. Consequently, multiple imputation was conducted with the data 
provided by 85 participants to analyse missing data and input substituted values (Rubin, 1987; Schaffer, 1997). Five iterations of imputation were performed (Schaffer, 1997).

\section{Clinical Characteristics of Sample}

Descriptive statistics for all self-report measures used in the study are provided in Table 2. As can be seen in Table 2, all measures demonstrated acceptable levels of internal consistency ( $\alpha>$.6; Hair, Anderson, Tatham \& Black, 2006).

\section{[INSERT TABLE 2 HERE]}

Independent samples t-test showed no significant difference on SPIN scores between participants who completed the questionnaire online compared to those who did not $(t(91)=$ $.635, p=.527)$. Using the cut-off scores for social anxiety as recommended by the authors of the SPIN (Connor et al, 2000), most participant scores (47.1\%) lay in the 'None' category (> 20). A further 15 participants (17.6\%) scored within the 'Mild' category, 13 (15.3\%) scored within the 'Moderate' category, $10(11.8 \%)$ scored in the 'Severe' category, and $7(8.2 \%)$ participants were categorised as 'Very Severe'. Using the cut-offs provided by the scale authors (Zigmond \& Snaith, 1983), 70.6\% of the sample showed clinically significant levels of anxiety (with $21.2 \%$ in the severe category) while $63.5 \%$ of the sample showed clinically significant levels of depression (with $20 \%$ in the severe category).

\section{Correlational Analysis}

Correlational analysis (Pearson's $r$ ) was conducted on the pooled dataset comprising of all iterations of the multiple imputation process (Rubin, 1987). Correlations are shown in Tables 3 and 4 .

\section{[INSERT TABLE $3 \& 4$ HERE]}

The following variables correlated significantly $(p<.05)$ with higher SA scores on the SPIN: not being employed $(r=.239, p=.028)$; higher levels of cognitive problems $(r=$ $.476, p<.001)$; higher levels of internal $(r=.248, p=.022)$ and chance $(r=.217, p=.046)$ 
LOC; lower self-esteem $(r=-.441, p<.001)$; lower self-efficacy $(r=-.472, p<.001)$; higher perceived stigma $(r=.654, p<.001)$; higher levels of anxiety $(r=.726, p<.001)$ and higher levels of depression $(r=.516, p<.001)$. Age, gender, time since TBI, time in hospital, living alone, relationship status and the two Powerful Others subscales of the MHLoC (Doctors and Others) did not significantly correlate with SA scores.

\section{Hierarchical Multiple Regression Analysis}

Hierarchical multiple regression analysis was conducted to examine if the predictor variables were able to explain the variance in SA scores. Predictor variables which correlated with SA demonstrating a small effect size or above (Pearson's $r>0.1$ ) were entered into the regression model. Predictor variables were entered into the regression model in three blocks: (a) demographic variables (gender, employment status); (b) clinical variables (time since TBI, perceived cognitive problems, depression); (c) psychological variables (MHLoC internal, MHLoC chance, self-esteem, self-efficacy, perceived stigma).

The overall model was significant, both with the original dataset $(F(2,63)=5.918, p$ $<.001$, explaining $51.8 \%\left(R^{2}=.518, R^{2}{ }_{\text {adj }}=.431\right)$ of the variance in SA scores and across all five imputations of missing data, with $F(2,82)$ values ranging from 8.006 to 8.799 , with all values of $p<.001$. The amount of variance in SA scores explained ranged from $52 \%\left(R^{2}=\right.$ $\left..520, R_{a d j}^{2}=.455\right)$ to $54.3 \%\left(R^{2}=.543, R_{a d j}^{2}=.481\right)$ of the variance in SA scores.

The Durbin-Watson values across the imputations ranged from 1.962 to 2.000 compared to the value from the original data of 1.846 , and therefore it was assumed there was no autocorrelation of residuals (Field, 2013). Examination of the VIF, tolerance and eigenvalues confirmed that there was no evidence of collinearity within the dataset (Bowerman \& O'Connell, 1990; Menard, 1995; Field, 2013). Graphical representation of the data suggested that assumptions of homoscedasticity and normally distributed residuals could be upheld. 
Block one (demographic variables) accounted for $10.3 \%\left(R^{2}=.103, R_{\text {adj }}^{2}=.074, p=\right.$ $.033)$ of the variance in SA scores in the original dataset, rising to between $11.9 \%\left(R^{2}=.119\right.$, $\left.R_{\text {adj }}^{2}=.097, p=.006\right)$ and $14.7 \%\left(R^{2}=.147, R^{2}\right.$ adj $\left.=.126, p=.001\right)$ following imputation. The addition of block two (clinical variables) made a significant contribution to the model, increasing the total variance explained to $36.1 \%\left(\Delta R^{2}=.259, p<.001\right)$ for the original dataset and between $39.8 \%\left(\Delta R^{2}=.279, p<.001\right)$ and $41.3 \%\left(\Delta R^{2}=.280, p<.001\right)$ following imputation, with significant changes in $F(p<.001)$ for both original and imputed data. Within this block of variables, standardised beta values across imputations indicated that higher levels of perceived cognitive problems $(\beta=.249$ to $.253, p=.012)$ and depression $(\beta=.348$ to $.367, p<.001)$ were significant independent predictors of higher reported SA, with time since injury not statistically significant $(\beta=.055$ to $.064, p=.516)$.

The addition of block three (psychological variables) also made a significant contribution to the overall model, explaining an additional $15.7 \%\left(\Delta R^{2}=.157, p<.001\right)$ of the total variance for the original dataset and between $12.2 \%\left(\Delta R^{2}=.122, p<.001\right)$ and $13 \%$ $\left(\Delta R^{2}=.130, p<.001\right)$ for each imputation. The change in $F$ associated with the addition of block three was statistically significant for both original $(p=.007)$ and imputed data $(p=$ .002 to .004$)$.

For individual predictors of SA, the overall model including all three blocks (and based on data pooled from all imputations) indicated that only higher levels of perceived stigma significantly predicted higher levels of SA $(B=.274, \beta=.334$ to $.341, t=2.789, p=$ $.005)$. In the final model, reported cognitive problems and depression ceased to meet criteria for statistical significance. In terms of the amount of variance explained by the other psychological variables, standardised beta values across imputations suggested that the internal subscale of the MHLoC $(\beta=.116$ to .123$)$ and self-esteem $(\beta=-.090$ to -.124$)$ predicted more variance in SA than self-efficacy $(\beta=-.050$ to -.070$)$ and the chance subscale 
of the MHLoC ( $\beta=.047$ to .061$)$. However, internal LoC and self-esteem were not statistically significant independent predictors of SA.

\section{Discussion}

\section{Key findings}

The present study examined psychological variables associated with SA following TBI. The overall regression model was significant, and the hypothesis that psychological variables would account for a significant proportion of the variance in SA was supported. The overall regression model sas signifieant and the addition of psychologieal variables (MHIOC internal, MHEOC chanee, self-esteem, self-effieacy, pereeived stigma) made a signifieant additional contribution to the amount of varianee explained, suggesting that psychologieal variables are important factors in the development of SA following TBI in addition to demographic and clinical variables.-Over half the sample (52.9\%) showed clinically significant levels of SA, as defined using the cut-off provided by the scale author (Connor et al., 2000). This is substantially higher than both the estimated prevalence rate of $12 \%$ observed in the general population (NICE, 2013) and the rate of $30.6 \%$ found with a sample of people diagnosed with another chronic neurological condition, multiple sclerosis (Poder et al., 2013).

Before psychological variables were added to the regression model, severity of perceived cognitive problems and depression were significant predictors of greater levels of SA. Depression is often comorbid with SA in the general population (Ohayon, Schatzberg, 2010), with negative beliefs about the self and others central to cognitive understandings of both presentations. Additionally, it is understandable that people who perceive more severe levels of cognitive impairment might have more negative evaluations of themselves as social objects, thereby experiencing higher levels of social anxiety. This has been highlighted in qualitative research with people who have experienced TBI (Morris et al., 2005; Nochi, 
1998); worry that other people will think they are slow or stupid has the potential to increase anxiety in social situations. Anxiety may also further reduce available attentional and cognitive processing capacity (which may already be decreased following TBI), thereby heightening and maintaining the problems experienced and the development of avoidance patterns. In this respect, perception of cognitive problems and low mood are clearly important clinical factors to consider in understanding the development and maintenance of SA.

\section{The addition of psychological variables (MHLoC internal, MHLoC chance, self-} esteem, self-efficacy, perceived stigma) made a significant additional contribution to the amount of variance explained, suggesting that psychological variables are important factors in the development of SA following TBI in addition to demographic and clinical variables. In the overall model (i.e., where the available variance was shared across a greater number of predictor variables), only perceived stigma was a significant independent predictor of SA. All other psychological variables explained some variance in SA, with internal LoC and selfesteem predicting a greater amount of variance than self-efficacy and chance LoC. Although internal LoC and self-esteem did not reach statistical significance as independent predictors, this may be due to the relatively small sample size employed in the study and further examination is warranted. Nevertheless, when self-esteem, self-efficacy and LoC are combined with perceived stigma they explain a significant amount of variance in SA, above and beyond that explained by demographic and clinical factors such as depression and perceived cognitive problems. It should also be noted that adding these variables as the final block in the regression model provides a particularly rigorous and robust test of their predictive power.

As outlined above, there is no previous research directly examining the role of psychological variables in the development of SA following TBI. However, the results are in keeping with theoretical and empirical understandings of psychological and psychosocial 
functioning following TBI. Indeed, there is growing consensus that psychological wellbeing and psychosocial functioning following TBI is influenced by a broad range of factors, with psychological variables playing a key role alongside cognitive, neurological and demographic factors (Soo et al., 2012; Moore et al., 2006; Kendall \& Terry, 1996).

Furthermore, the emergence of perceived stigma as a significant independent predictor is a key finding. This offers support for Kendall and Terry's (1996) model of psychosocial functioning after TBI, in which perceived stigma is proposed as a key factor affecting primary appraisal (i.e., how events are appraised), which subsequently affects secondary appraisal (i.e., a person's beliefs around how well they can cope with an event). This finding is also consistent with theoretical models highlighting how aversive social experiences are a key factor in the development of SA (Rapee \& Spence, 2004). The cognitive model of SA, proposed by Clark and Wells (1995) and updated by Wells (2013), proposes that social situations activate negative automatic thoughts based on assumptions around perceived danger in social situations. Negative evaluations of how the self is processed as a social object (i.e., how the person thinks they appear to others) are often inaccurate or exaggerated and can lead to safety behaviours (e.g., avoidance), which serve to reinforce the beliefs (Wells, 2013). Safety behaviours maintain and exacerbate the problems by perpetuating the beliefs that social interactions will lead to negative outcomes (Clark \& Wells, 1995; Wells, 2013; Banerjee \& Henderson, 2001). Since social experiences are key to the development and maintenance of SA, it is consistent that perceived stigma would play a key role in the development of SA. As discussed above, greater levels of perceived cognitive problems and reduced mood are also likely to be important factors in the development of such problem cycles.

These findings are also consistent with social models of disability, which highlight the need to focus on the societal context of impairment (Oliver, 1983; 2004). Instead of focusing 
on the functional impairments of the individual, the social model considers disability to be caused by the economic, cultural and environmental barriers which are faced by people with physical or cognitive impairments. Consistent with the findings of the present study, Oliver (2004) discusses how cultural norms around disability, which view impairment as unattractive and unwanted, negatively impact people by creating stigmatising, discriminatory environments which devalue and actively disable people with impairments, thereby causing psychological distress. Individualistic psychiatric or psychological approaches often fail to take this into account, instead conceptualising psychological problems as a consequence of the impairment itself and focusing on the need for people to seek treatment or adapt to the disabling environment (Simpson \& Thomas, 2014; Simpson, McMillan \& Reeve, 2013).

Moreover, people who develop impairments throughout their lives have been raised within these cultural norms (Oliver, 2004). The term psychoemotional disablism refers to how negative social interactions can lead to negative societal stereotypes about what it means to have an impairment being internalised, which can limit the coping resources people have to draw on and lead to reduced participation in society (Reeve, 2012; Simpson et al., 2013). Research has highlighted how stigma and poor understanding are key problems in relation to TBI (e.g., Linden \& Boylan, 2010; McClure, 2011; Guilmette \& Paglia, 2004). In emphasising the role of stigma in the development of SA following TBI, this study highlights the importance of considering the societal and cultural factors influencing a person's experience of impairment following TBI, guiding intervention at both an individual and social level.

\section{Clinical implications}

These findings have various implications for health professionals. It appears that SA is a problem following TBI and the application of cognitive models of SA to therapeutic work may be a useful way to conceptualise problems with psychosocial functioning 
following TBI. The clear role for psychological factors such as self-esteem, self-efficacy and LoC in the development of SA following TBI suggests a need to consider these variables during physical and cognitive assessment and rehabilitation, supporting the development of an individual's psychological resilience during the complex process of recovery from TBI.

In particular, the significant role which stigma plays in the development of SA following TBI highlights the importance of developing contextually inclusive formulations (BPS, 2011) which explore the reactions people experience from others, in addition to the individual psychological factors which affect how responses of other people are perceived. By considering the ways in which disability is constructed by the discriminatory social context faced by people who have experienced TBI and not focusing solely on the individual, interventions which challenge the lack of knowledge and negative attitudes around TBI (Linden \& Boylan, 2010; McClure, 2011; Guilmette \& Paglia, 2004) can begin to address the barriers, discrimination and stigma which are often imposed through entrenched societal and cultural norms (Simpson \& Thomas, 2014; Oliver, 2004). Indeed, the precise nature of the stigma being experienced is important. For example, this study highlights the importance of perceived cognitive impairment; specific cognitive impairments following TBI may be misunderstood as a reduction in overall intellectual ability and functional independence. Educational programmes could highlight the difference between general intellectual ability and the types of cognitive problems that can be experienced after TBI, along with ways in which the individual and the people around them can reduce the impact these problems might have on their life.

\section{Limitations and Implications for Future Research}

It is recognised that the use of a self-selecting sample may have introduced some bias to the sample. The study also focused exclusively on people living in the community. A different pattern of results may be evident with a sample in the earlier stages of recovery and 
future research may be useful in exploring how different kinds of interactions with professionals at an early stage affect the development of SA. Moreover, this study focused on TBI to explore specific issues relating to this population. Further research which widens the scope of the study to include people with other kinds of acquired brain injuries may increase the generalisability of these findings to clinical practice.

Furthermore, the cross-sectional nature of the study limits the potential for understanding how SA and the other variables under examination may change over time. Consequently, future research which utilises a longitudinal or prospective design would be of value. In addition, the use of multiple regression in the current study assumes a linear relationship between variables. However, as psychological variables have been shown to play a significant role in the development of SA, use of more advanced statistical techniques (e.g., structural equation modelling) would be useful next step following this study. For example, the regression model suggests that perceived stigma is predictive of SA, however it is possible that this is a bi-directional relationship and that people who are more anxious in social situations are likely to be hyper-vigilant to threat, thereby perceiving higher levels of stigmatising behaviour from others. Further research analysing hypothesised pathways between factors will allow for a more detailed understanding of the complex bi-directional interactions between predictor and outcome variables. This will be useful in guiding intervention, in that targeting particular variables (e.g., self-esteem) in therapy may help to reduce the amount of stigma which is perceived, mitigating its effect on SA.

Furthermore, the lack of characterisation of the sample in terms of objective severity of injury and cognitive impairment is a limitation of the study. Perceived severity of cognitive problems may not be accurate and the self-selected sample may potentially result in a less impaired group. However, injury variables and degree of cognitive impairment do not fully account for variance in psychosocial adjustment following TBI (Antonak et al., 1993) 
and appraisal of cognitive limitations has been shown to moderate the relationship between injury severity and psychosocial function (Kervick \& Kaemingk, 2005). Therefore, by assessing subjective severity of cognitive problems using a self-report measure, the degree to which an individual's appraisal of their cognitive problems can contribute to SA can be explored. Future research employing other methods of assessing neurological and cognitive variables would be useful, for example using neuropsychological assessments to assess impairments in specific cognitive domains, or consulting medical records to obtain specific details of TBI severity. Further examination of other relevant psychological variables such as appraisal and coping style would also be of value, given the relevance of such factors in relation to wellbeing following TBI (Anson \& Ponsford, 2006a; Kendall \& Terry, 1996).

The present study also did not explore situational factors in detail. Although living alone and being in a relationship did not significantly correlate with SA in this study, future research might address environmental factors hypothesised to be of importance for psychosocial wellbeing following TBI (Kendall \& Terry, 1996). For example, social contact, family dynamics and perceptions of support from others might be important variables to consider in the development of SA following TBI, particularly as social learning theories of SA suggest that experience of aversive situations and lack of modelling of adaptive coping strategies for managing social situations are key to the development of SA (Rapee \& Spence, 2004). Longitudinal research examining relationships post-TBI may be extremely useful in understanding SA and psychosocial wellbeing more broadly.

Even considering the limitations discussed above, the present study is the first to examine factors associated with SA following TBI. The findings of this study highlight the importance of considering SA in this population, particularly when considering rehabilitation adjustment following TBI. The significance of perceived stigma as a predictor of SA is an important finding in this context, highlighting a clear role for clinical psychologists and other 
rehabilitation professionals to integrate social models of disability into their practice and make a valued contribution to the psychological wellbeing of people who have experienced TBI.

\section{Conclusion}

The current study explored factors predicting SA following TBI. Hierarchical multiple regression was used to examine the extent to which demographic, clinical and psychological variables predicted scores on a measure of SA. Psychological variables, particularly perceived stigma, explained a significant proportion of the variance in SA. Therefore it is proposed that psychological variables are important factors affecting the development of SA following TBI, above and beyond demographic and clinical variables.

The study provides empirical support to the theoretical rationale for SA following TBI proposed by Soo et al. (2012) and Moore et al. (2006), highlighting the potential application of Kendall and Terry's (1996) model for psychosocial adjustment. Further research is required to examine the complex relationships between such variables using a more stable regression model, and to explore in more detail other variables which may have an influence on SA using more advanced statistical techniques which allow for the examination of nonlinear relationships. 


\section{References}

Alonso, J., Buron, A., Bruffaerts, R., He, Y., Posada, Villa, J., Lepine, J. P., ... \& Von Korff, M. (2008). Association of perceived stigma and mood and anxiety disorders: results from the World Mental Health Surveys. Acta Psychiatrica Scandinavica, 118(4), 305-314. doi:10.1111/j.1600-0447.2008.01241.x

American Psychiatric Association. (2013). Diagnostic and statistical manual of mental disorders (5th ed.). Washington DC: American Psychiatric Association.

Anderson, K. N., Jeon, A. B., Blenner, J. A., Wiener, R. L., \& Hope, D. A. (2015). How people evaluate others with social anxiety disorder: A comparison to depression and general mental illness stigma. American Journal of Orthopsychiatry, 85(2), 131-138. doi:10.1037/ort0000046

Anderson, V.A., Catroppa, C., Dudgeon, P., Morse, S.A., Haritou, F., Rosenfeld, J.V. (2006). Understanding predictors of functional recovery and outcome 30 months following early childhood head injury. Neuropsychology, 20(1), 42-57. doi:10.1037/0894-4105.20.1.42

Anson, K., \& Ponsford, J. (2006a). Coping and Emotional Adjustment Following Traumatic Brain Injury. The Journal of Head Trauma Rehabilitation, 21(3). doi:10.1097/00001199200605000-00005

Anson, K., \& Ponsford, J. (2006b). Who benefits? Outcome following a coping skills group intervention for traumatically brain injured individuals. Brain Injury, 20(1), 1-13. doi:10.1080/02699050500309791

Antonak, R. F., Livneh, H., \& Antonak, C. (1993). A review of research on psychosocial adjustment to impairment in persons with traumatic brain injury. The Journal of Head Trauma Rehabilitation, 8(4). doi:10.1097/00001199-199312000-00009 
Antony, M. M., Coons, M. J., McCabe, R. E., Ashbaugh, A., \& Swinson, R. P. (2006). Psychometric properties of the social phobia inventory: Further evaluation. Behaviour Research and Therapy, 44(8), 1177-1185. doi:10.1016/j.brat.2005.08.013

Banerjee, R., \& Henderson, L. (2001). Social-cognitive factors in childhood social anxiety: A preliminary investigation. Social Development, 10(4), 558-572. doi:10.1111/14679507.00180

Bedard, M., Felteau, M., Gibbons, C., Klein, R., Mazmanian, D., Fedyk, K., \& Mack, G. (2005). A mindfulness-based intervention to improve quality of life among individuals who sustained traumatic brain injuries: One-year follow-up. The Journal of Cognitive Rehabilitation, 25(13), 8-13. doi:10.1080/0963828031000090489

Bennett, D. A. (2001). How can I deal with missing data in my study? Australian and New Zealand Journal of Public Health, 25(5), 464-469. doi:10.1111/j.1467-842X.2001.tb00294.x

Beyenburg, S., Mitchell, A. J., Schmidt, D., Elger, C. E., \& Reuber, M. (2005). Anxiety in patients with epilepsy: Systematic review and suggestions for clinical management. Epilepsy \& Behavior, 7(2), 161-171. doi:10.1016/j.yebeh.2005.05.014

Bjelland, I., Dahl, A. A., Haug, T. T., \& Neckelmann, D. (2002). The validity of the Hospital Anxiety and Depression Scale. An updated literature review. Journal of Psychosomatic Research, 52(2), 69-77. doi:10.1016/s0022-3999(01)00296-3

Bowerman, B. L., \& O’Connell, R. T. (1990). Linear statistical models: An applied approach. Belmont, CA: Duxbury.

British Psychological Society (2008). Conducting research with people not having the capacity to consent to their participation. Leicester, England: British Psychological Society.

British Psychological Society (2011). Good Practice Guidelines on the use of psychological formulation. Leicester, England: British Psychological Society. 
Brockfield, K. C., Perini, S. J., and Rapee, R. M. (2014). Social Anxiety and Social Anxiety Disorder Across Cultures. In S. G. Hofmann, P. M. DiBartolo (Eds.), Social Anxiety: Clinical, Developmental, and Social Perspectives. London, England: Academic Press.

Bryant, R. A., O' Donnell, M. L., Creamer, M., McFarlane, A. C., Clark, C. R., \& Silove, D. (2010). The psychiatric sequelae of traumatic injury. American Journal of Psychiatry, 167(3), 312320. doi:10.1176/appi.ajp.2009.09050617

Catroppa, C., Anderson, V. A., Morse, S. A., Haritou, F., \& Rosenfeld, J. V. (2008). Outcome and Predictors of Functional Recovery 5 Years Following Pediatric Traumatic Brain Injury (TBI). Journal of Pediatric Psychology, 33(7), 707-718. doi:10.1093/jpepsy/jsn006

Cicerone, K. D., \& Azulay, J. (2007). Perceived self-efficacy and life satisfaction after traumatic brain injury. The Journal of Head Trauma Rehabilitation, 22(5), 257-266.

doi:10.1097/01.htr.0000290970.56130.81

Clark, D. M., \& Wells, A. (1995). A cognitive model of social phobia. In M. R. Liebowitz (Eds.), Social phobia: Diagnosis, assessment, and treatment, (pp. 69-93). New York, NY: Guilford Press.

Cloitre, M., Heimberg, R. G., Liebowitz, M. R., \& Gitow, A. (1992). Perceptions of control in panic disorder and social phobia. Cognitive Therapy and Research, 16(5), 569-577. doi:10.1007/BF01175142

Coe, R. (2002). It's the Effect Size, Stupid: What effect size is and why it is important. Paper presented at the Annual Conference of the British Educational Research Association, University of Exeter, England. Retrieved from www.cem.org/attachments/ebe/ESguide.pdf/

Cohen, J. (1988). Statistical power analysis for the behavioral sciences $\left(2^{\text {nd }}\right.$ ed.). Hillsdale, NJ: Erlbaum. 
Connor, K. M., Davidson, J., Churchill, L. E., Sherwood, A., Weisler, R., \& Fox, E. (2000).

Psychometric properties of the Social Phobia Inventory (SPIN): New self-rating scale. The British Journal of Psychiatry, 176(4), 379-386. doi:10.1192/bjp.176.4.379

Crome, E., Grove, R., Baillie, A. J., Sunderland, M., Teesson, M., \& Slade, T. (2014). DSM-IV and DSM-5 social anxiety disorder in the Australian community. Australian \& New Zealand Journal of Psychiatry, 49(3), 227-235. doi:10.1177/0004867414546699

Downing, M. G., Stolwyk, R., \& Ponsford, J. L. (2013). Sexual Changes in Individuals With Traumatic Brain Injury. The Journal of Head Trauma Rehabilitation, 28(3), 171-178. doi:10.1097/HTR.0b013e31828b4f63

Field, A. (2013). Discovering Statistics using IBM SPSS Statistics. London, England: Sage.

Goldstein, L. H., \& McNeil, J. E. (2012). Clinical Neuropsychology. Sussex, England: John Wiley \& Sons.

Gould, K.R., Ponsford, J.L., Johnston, L., Schönberg, M. (2011). The nature, frequency and course of psychiatric disorders in the first year after traumatic brain injury: a prospective study. Psychological Medicine, 41(10), 2099-2109. doi:10.1017/S003329171100033X

Gracey, F., Evans, J. J., \& Malley, D. (2009). Capturing process and outcome in complex rehabilitation interventions: A "Y-shaped" model. Neuropsychological Rehabilitation, 19(6), 867-890. doi:10.1080/09602010903027763

Graham, J. W. (2009). Missing Data Analysis: Making It Work in the Real World. Annual Review of Psychology, 60(1), 549-576. doi:10.1146/annurev.psych.58.110405.085530

Guilmette, T. J., \& Paglia, M. F. (2004). The public's misconceptions about traumatic brain injury: A follow up survey. Archives of Clinical Neuropsychology, 19(2), 183-189. doi:10.1016/s0887$6177(03) 00025-8$

Guindon, M. (2002). Toward accountability in the use of the self-esteem construct. Journal of Counseling and Development, 80(2), 204-214. doi:10.1002/j.1556-6678.2002.tb00184.x 
Hair, J., Anderson, R., Tatham, R., \& Black, W. (2006). Multivariate Data Analysis. New Jersey, NJ: Pearson/Prentice Hall.

Hemphill, J. F. (2003). Interpreting the magnitudes of correlation coefficients. American Psychologist, 58(1), 78-79. doi:10.1037/0003-066X.58.1.78

Hiott, D. W., \& Labbate, L. (2002). Anxiety disorders associated with traumatic brain injuries. Neuro Rehabilitation, 17(4), 345-355.

Hodgson, J., McDonald, S., Tate, R., \& Gertler, P. (2012). A Randomised Controlled Trial of a Cognitive-Behavioural Therapy Program for Managing Social Anxiety After Acquired Brain Injury. Brain Impairment, 6(3), 169-180. doi:10.1375/brim.2005.6.3.169

Horton, N. J., Lipsitz, S. R., \& Parzen, M. (2003). A potential for bias when rounding in multiple imputation. The American Statistician, 57(4), 229-232. doi:10.1198/0003130032314

Jones, J., Haslam, A., Jetten, J., Williams, H., Morris, R., \& Saroyan, S. (2010). That which doesn't kill us can make us stronger (and more satisfied with life): The contribution of personal and social changes to well-being after acquired brain injury. Psychology \& Health, 26(3), 353369. doi: $10.1080 / 08870440903440699$

Jones, J., Williams, H., Jetten, J., Haslam, A., Harris, A., \& Gleibs, I.H. (2012). The role of psychological symptoms and social group memberships in the development of post-traumatic stress after traumatic injury. British Journal of Health Psychology, 17(4), 798-811. doi:10.1111/j.2044-8287.2012.02074.x

Kelly, D. F., \& Becker, D. P. (2001). Advances in management of neurosurgical trauma: USA and Canada. World Journal of Surgery, 25(9), 1179-1185. doi: 10.1007/s00268-001-0080-x

Kendall, E., \& Terry, D. (1996). Psychosocial adjustment following closed head injury: A model for understanding individual differences and predicting outcome. Neuropsychological Rehabilitation, 6(2), 101-132. doi:10.1080/713755502 
Kennedy, B. L., Lynch, G. V., \& Schwab, J. J. (1998). Assessment of locus of control in patients with anxiety and depressive disorders. Journal of Clinical Psychology, 54(4), 509-515. doi:10.1002/(SICI)1097-4679(199806)54:4

Kervick, R. B., \& Kaemingk, K. L. (2005). Cognitive appraisal accuracy moderates the relationship between injury severity and psychosocial outcomes in traumatic brain injury. Brain Injury, 19(11), 881-889. doi:10.1080/02699050400025273

Kessler, R. C., Berglund, P., Demler, O., Jin, R., Merikangas, K. R., \& Walters, E. E. (2005). Lifetime Prevalence and Age-of-Onset Distributions of DSM-IV Disorders in the National Comorbidity Survey Replication. Archives of General Psychiatry, 62(6), 593. doi:10.1001/archpsyc.62.6.593

Kim, E., Lauterbach, E.C., Reeve, A., Arciniegas, D.B., Coburn, K.L., Mendez, M.F., ... Coffey, E.C. (2007). Neuropsychiatric complications of traumatic brain injury: a critical review of the literature (a report by the ANPA Committee on Research). Journal of Neuropsychiatry and Clinical Neuroscience, 19(2), 106-127. doi: 10.1176/jnp.2007.19.2.106

Kolb, B., \& Whishaw, I.Q. (2003). Fundamentals of human neuropsychology (5 $5^{\text {th }}$ ed.). New York, NY: Worth Publishers.

Konrad, C., Geburek, A.J., Rist, F., Blumenroth, H., Fischer, B., Husstedt, I., ...Lohmann, H. (2010). Long-term cognitive and emotional consequences of mild traumatic brain injury. Psychological Medicine, 41(6), 1197-211. doi:10.1017/S0033291710001728

Leary, M. R., \& Atherton, S. C. (1986). Self-efficacy, social anxiety, and inhibition in interpersonal encounters. Journal of Social and Clinical Psychology, 4(3), 256-267. doi:10.1521/jscp.1986.4.3.256

Leary, M. R., \& Baumeister, R. F. (2000). The nature and function of self-esteem: Sociometer theory. In M. P. Zanna (Eds.), Advances in Experimental Social Psychology, 32, 1-62. doi:10.1016/S0065-2601(00)80003-9 
Levack, W.M., Kayes, N.M., Fadyl, J. K. (2010). Experience of recovery and outcome following traumatic brain injury: A metasynthesis of qualitative research. Disability and Rehabilitation, 32(12), 986-999. doi: 10:3109/09638281003775394

Linden, M. A., \& Boylan, A. M. (2010). 'To be accepted as normal': Public understanding and misconceptions concerning survivors of brain injury. Brain Injury, 24(4), 642-650. doi:10.3109/02699051003601689

Little, R. J. (1988). A test of missing completely at random for multivariate data with missing values. Journal of the American Statistical Association, 83(404), 1198-1202. doi:10.1080/01621459.1988.10478722

Mattson, A., \& Levin, H. (1990). Frontal lobe dysfunction following closed head injury. A review of the literature. The Journal of Nervous and Mental Disease, 178(5). doi:10.1097/00005053199005000-00002

McClure, J. (2011). The role of causal attributions in public misconceptions about brain injury. Rehabilitation Psychology, 56(2), 85-93. doi:10.1037/a0023354

McDowell, R. D., Ryan, A., Bunting, B. P., O'Neill, S. M., Alonso, J., Bruffaerts, R. ... Tomov, T. (2013). Mood and anxiety disorders across the adult lifespan: A European perspective. Psychological Medicine, 44(4), 707-722. doi:10.1017/S0033291713001116

Menard, S. (1995). Applied logistic regression analysis. California, CA: Sage.

Menon, D. K., Schwab, K., Wright, D. W., \& Maas, A. I. (2010). Position Statement: Definition of Traumatic Brain Injury. Archives of Physical Medicine and Rehabilitation, 91(11), 16371640. doi:10.1016/j.apmr.2010.05.017

Moore, A. D., \& Stambrook, M. (1992). Coping strategies and locus of control following traumatic brain injury: relationship to long-term outcome. Brain Injury, 6(1), 89-94. doi: $10.3109 / 02699059209008129$ 
Moore, Terryberry-Spohr, L., \& Hope, D. A. (2006). Mild traumatic brain injury and anxiety sequelae: A review of the literature. Brain Injury, 20(2), 117-132. doi: $10.1080 / 02699050500443558$

Morris, P. G., Prior, L., Deb, S., Lewis, G., Mayle, W., Burrow, C. E., \& Bryant, E. (2005). Patients' views on outcome following head injury: A qualitative study. BMC Family Practice, 6(1), 30. doi: 10.1186/1471-2296-6-30

Morton, M. V., \& Wehman, P. (1995). Psychosocial and emotional sequelae of individuals with traumatic brain injury: a literature review and recommendations. Brain Injury, 9(1), 81-92. doi: $10.3109 / 02699059509004574$

National Institute for Health and Care Excellence. (2013). Social Anxiety Disorder: The NICE Guideline on Recognition, Assessment and Treatment. Retrieved from http://www.nice.org.uk/nicemedia/live/14168/63846/63846.pdf

National Institute for Health and Care Excellence. (2014). Head injury: Triage, assessment, investigation and early management of head injury in children, young people and adults. Retrieved from https://www.nice.org.uk/guidance/cg176/

Neuro-QOL (2010). Neuro-QOL report: Item Bank Development and Item Response Theory Statistics. Retrieved from http://www.neuroqol.org/Resources/Resources\%20documents/Neuro-QOL-Tech\%20Rept2013.pdf/

Neuro-QOL (2012). Adult item banks. Accessed online at http://www.neuroqol.org/WhatandWhy/ItemBanks/Adults\%20Item\%20BAnks/Pages/default. aspx/

Newton, A., \& Johnson, D. A. (1985). Social adjustment and interaction after severe head injury. The British Journal of Clinical Psychology, 24(4), 225-234. doi:10.1111/j.20448260.1985.tb00655.x 
Nochi, M. (1998). "Loss of self" in the narratives of people with traumatic brain injuries: A qualitative analysis. Social Science \& Medicine, 46(7), 869-878. doi:10.1016/S02779536(97)00211-6

Ohayon, M.M., Schatzberg, A.F. (2010). Social phobia and depression: prevalence and comorbidity. Journal of Psychosomatic Research, 68(3), 235-243. doi: 10.1016/j.jpsychores.2009.07.018.

Oliver, M. (1983). Social Work with Disabled People. Basingstoke, England: Macmillan.

Oliver, M. (2004). The social model in action: If I had a hammer. In C. Barnes, G. Mercer (Eds.), Implementing the social model of disability: theory and research (pp. 18-31). Leeds, England: The Disability Press.

Osborn, A.J., Mathias, J.L., \& Fairweather-Schmidt, A.K. (2014). Depression following adult, nonpenetrating traumatic brain injury: A meta-analysis examining methodological variables and sample characteristics. Neuroscience \& Biobehavioral Reviews, 47, 1-15. doi:10.1016/j.neubiorev.2014.07.007

Ownsworth, T. (2014). Self-identity after brain injury. New York, NY: Psychology Press.

Pierce, C. A., \& Hanks, R. A. (2006). Life Satisfaction After Traumatic Brain Injury and the World Health Organization Model of Disability. American Journal of Physical Medicine \& Rehabilitation, 85(11). doi:10.1097/01.phm.0000242615.43129.ae

Poder, K., Ghatavi, K., Fisk, J. D., Campbell, T. L., Kisely, S., Sarty, I., ... Bhan, V. (2009). Social anxiety in a multiple sclerosis clinic population. Multiple Sclerosis, 15(3), 393-398. doi: $10.1177 / 1352458508099143$

Ponsford, J.L., Downing, M., Olver, J., Ponsford, M., Acher, R., Carty, M., \& Spitz, G. (2014). Longitudinal Follow-Up of Patients with Traumatic Brain Injury: Outcome at Two, Five, and Ten Years Post-Injury. Journal of Neurotrauma, 31(1), 64-77. doi: 10.1089/neu.2013.2997 
Ponsford, J., Kelly, A., \& Couchman, G. (2014). Self-concept and self-esteem after acquired brain injury: A control group comparison. Brain Injury, 28(2), 146-154. doi:10.3109/02699052.2013.859733

Qualtrics (2013). Qualtrics Survey Software. [Software]. Available from http://www.qualtrics.com/ Rao, D., Choi, S. W., Victorson, D., Bode, R., Peterman, A., Heinemann, A., \& Cella, D. (2009). Measuring stigma across neurological conditions: the development of the stigma scale for chronic illness (SSCI). Quality of Life Research, 18(5), 585-595. doi:10.1007/s11136-009$9475-1$

Rao, V., \& Lyketsos, C. G. (2002). Psychiatric aspects of traumatic brain injury. Psychiatric Clinics of North America, 25(1), 43-69. doi:10.1016/s0193-953x(03)00052-2

Rapee, R. M., \& Spence, S. H. (2004). The etiology of social phobia: Empirical evidence and an initial model. Clinical Psychology Review, 24(7), 737-767. doi:10.1016/j.cpr.2004.06.004

Reeve, D. (2012). Psycho-emotional disablism: the missing link? In N. Watson, A. Roulstone, \& C. Thomas (Eds.), Routledge Handbook of Disability Studies (pp. 78-93). London, England: Routledge.

Ritter, V., Ertel, C., Beil, K., Steffens, M. C., \& Stangier, U. (2013). In the Presence of Social Threat: Implicit and explicit self-esteem in social anxiety disorder. Cognitive Therapy and Research, 37(6), 1101-1109. doi:10.1007/s10608-013-9553-0

Rochat, L., Ammann, J., Mayer, E., Annoni, J.M., \& Van Der Linden, M. (2009). Executive disorders and perceived socio-emotional changes after traumatic brain injury. Journal of Neuropsychology, 3(2), 213-227. doi:10.1348/174866408X397656

Rosenberg, M. (1965). Society and the adolescent self-image. New Jersey, NJ: Princeton. Rosenberg, M. (1979). Conceiving the Self. New York, NY: Basic Books.

Rubin, D.B. (1987). Multiple Imputation for Nonresponse in Surveys. New York: Wiley.

Schafer, J.L. (1997) Analysis of Incomplete Multivariate Data. London, England: Chapman \& Hall. 
Scheutzow, M. H., \& Wiercisiewski, D. R. (1999). Panic disorder in a patient with traumatic brain injury: A case report and discussion. Brain Injury, 13(9), 705-714. doi: $10.1080 / 026990599121250$

Scholten, A.C., Haagsma, J.A., Cnossen, M.C., Olff, M., Van Beeck, E.F., \& Polinder, S. (2016). Journal of Neurotrauma, ahead of print. doi:10.1089/neu.2015.4252.

Simpson, J., McMillan, H., \& Reeve, D. (2013). Reformulating Psychological Difficulties in People with Parkinson's Disease: The Potential of a Social Relational Approach to Disablism. Parkinson's Disease, 2013(3), 1-8. doi:10.1002/mds.23462

Simpson, J., \& Thomas, C. (2014). Clinical psychology and disability studies: bridging the disciplinary divide on mental health and disability. Disability and Rehabilitation, 1-6. doi:10.3109/09638288.2014.961656

Sohlberg, M. M., \& Mateer, C. A. (2001). Cognitive rehabilitation: An integrative neuropsychological approach. New York, NY: Guilford Press.

Soo, C., \& Tate, R.L. (2009). Psychological treatment for anxiety in people with traumatic brain injury. Cochrane Database of Systematic Reviews, 3, 1-23. doi:10.1002/14651858.CD005239.pub2.

Soo, C., Tate, R. L., \& Rapee, R. M. (2012). Social anxiety and its treatment in children and adolescents with acquired brain injury. In V. Anderson \& M. Beauchamp (Eds.), Developmental social neuroscience and childhood brain insult: Theory and practice (pp. 370-388). New York, NY: Guildford.

Tate, R. L., \& Broe, G. A. (1999). Psychosocial adjustment after traumatic brain injury: What are the important variables? Psychological Medicine, 29(3), 1-13. doi:10.1017/S0033291799008466

Temkin, N. R., Corrigan, J. D., Dikmen, S. S., \& Machamer, J. (2009). Social functioning after traumatic brain injury. The Journal of Head Trauma Rehabilitation, 24(6), 460-467. doi:10.1097/htr.0b013e3181c13413 
Truelle, J. L., Fayol, P., Montreuil, M., \& Chevignard, M. (2010). Community integration after severe traumatic brain injury in adults. Current Opinion in Neurology, 23(6), 688-694. doi:10.1097/WCO.0b013e3283404258

Waldron, B., Benson, C., O' Connell, A., Byrne, P., Dooley, B., \& Burke, T. (2010). Health locus of control and attributions of cause and blame in adjustment to spinal cord injury. Spinal Cord, 48(8), 598-602. doi:10.1038/sc.2009.182

Wallston, K. A. (2005). The Validity of the Multidimensional Health Locus of Control Scales. Journal of Health Psychology, 10(5), 623-631. doi:10.1177/1359105305055304

Wallston, K. A., Stein, M. J., \& Smith, C. A. (1994). Form C of the MHLC scales: A ConditionSpecific Measure of Locus of Control. Journal of Personality Assessment, 63(3), 534-553. doi:10.1207/s15327752jpa6303_10

Wells, A. (2013). Cognitive Therapy of Anxiety Disorders. Chichester, England: John Wiley \& Sons. Whelan-Goodinson, R., Ponsford, J., \& Schönberger, M. (2009). Validity of the Hospital Anxiety and Depression Scale to assess depression and anxiety following traumatic brain injury as compared with the Structured Clinical Interview for DSM-IV. Journal of Affective Disorders, 114(3), 94-102. doi:10.1016/j.jad.2008.06.007

Whelan-Goodinson, R., Ponsford, J.L., Schönberger, M., \& Johnston, L. (2010). Predictors of psychiatric disorders following traumatic brain injury. Journal of Head Trauma Rehabilitation, 25(5), 320-9. doi:10.1097/HTR.0b013e3181c8f8e7

Williams, W. H., Evans, J. J., \& Fleminger, S. (2003). Neurorehabilitation and cognitive-behaviour therapy of anxiety disorders after brain injury: An overview and a case illustration of obsessive-compulsive disorder. Neuropsychological Rehabilitation, 13(1-2), 133-148. doi: $10.1080 / 09602010244000417$ 
Wilson, B. A. \& Gracey, F. (2009). Towards a comprehensive model of neuropsychological rehabilitation. In B. A. Wilson (Eds.), Neuropsychological rehabilitation: Theory, models, therapy and outcome. New York: Cambridge University Press.

World Health Organisation (2006). Neurological disorders: Public health challenges. Retrieved from http://www.who.int/mental_health/publications/neurological_disorders_ph_challenges/en/

Wright, J. C., \& Telford, R. (1996). Psychological problems following minor head injury: a prospective study. The British Journal of Clinical Psychology, 35(3), 399-412. doi:10.1111/j.2044-8260.1996.tb01194.x

Yeates, G. N., Gracey, F., \& Mcgrath, J. C. (2008). A biopsychosocial deconstruction of "personality change" following acquired brain injury. Neuropsychological Rehabilitation, 18(5-6), 566589. doi:10.1080/09602010802151532

Zigmond, A. S., \& Snaith, R. P. (1983). The hospital anxiety and depression scale. Acta Psychiatrica Scandinavica, 67(6), 361-370. doi:10.1111/j.1600-0447.1983.tb09716.x 
Table 1.

Demographic characteristics $(N=85)$

\begin{tabular}{|c|c|c|c|c|}
\hline & $\mathrm{n}$ & $\%$ & Mean (SD) & Range \\
\hline \multicolumn{5}{|l|}{ Gender } \\
\hline Male & 54 & $63.5 \%$ & & \\
\hline Female & 28 & $32.9 \%$ & & \\
\hline Other / prefer not to say & 3 & $3.5 \%$ & & \\
\hline Age & & & $42.4(13.34)$ & $19-81$ \\
\hline \multicolumn{5}{|l|}{ Cause of injury } \\
\hline Road traffic accident & 36 & $42.4 \%$ & & \\
\hline Assault & 11 & $12.9 \%$ & & \\
\hline Sport injury & 4 & $4.7 \%$ & & \\
\hline Work injury & 6 & $7.1 \%$ & & \\
\hline Trip / fall & 23 & $27.1 \%$ & & \\
\hline Other & 3 & $3.5 \%$ & & \\
\hline Prefer not to say & 2 & $2.4 \%$ & & \\
\hline Time since injury & & & 7.72 years $(8.73)$ & $0.37-33$ \\
\hline Time spent in hospital & & & 16.53 weeks (32.12) & $0-208$ \\
\hline \multicolumn{5}{|l|}{ Employed } \\
\hline Yes & 27 & $31.8 \%$ & & \\
\hline No & 57 & $67.1 \%$ & & \\
\hline Prefer not to say & 1 & $1.2 \%$ & & \\
\hline \multicolumn{5}{|l|}{ Live alone } \\
\hline Yes & 25 & $29.4 \%$ & & \\
\hline No & 59 & $69.4 \%$ & & \\
\hline Prefer not to say & 1 & $1.2 \%$ & & \\
\hline \multicolumn{5}{|l|}{ Relationship status } \\
\hline Single & 28 & $32.9 \%$ & & \\
\hline In a relationship & 44 & $51.8 \%$ & & \\
\hline Separated / divorced & 12 & $14.1 \%$ & & \\
\hline Other / prefer not to say & 1 & $1.2 \%$ & & \\
\hline \multicolumn{5}{|l|}{ Recruitment method } \\
\hline Online & 54 & $55.1 \%$ & & \\
\hline
\end{tabular}


Table 2.

Clinical characteristics of sample

\begin{tabular}{|c|c|c|c|c|}
\hline & Mean (SD) & Range & n (\%) & $\alpha$ \\
\hline \multicolumn{5}{|l|}{ Social Phobia Inventory (SPIN) } \\
\hline Total & $25.67(16.88)$ & $0-68$ & $85(100 \%)$ & .944 \\
\hline None $(<20)$ & & & $40(47.1 \%)$ & \\
\hline Mild social anxiety $(21-30)$ & & & $15(17.6) \%$ & \\
\hline Moderate social anxiety $(31-40)$ & & & $13(15.3 \%)$ & \\
\hline Severe social anxiety $(41-50)$ & & & $10(11.8 \%)$ & \\
\hline Very severe social anxiety $(>51)$ & & & $7(8.2 \%)$ & \\
\hline Applied Cognition* & $67.62(17.41)$ & $28-90$ & $85(100 \%)$ & .960 \\
\hline \multicolumn{5}{|l|}{ Multidimensional Health Locus of Control } \\
\hline \multicolumn{5}{|l|}{$($ MHLoC )* } \\
\hline Internal subscale & $21.61(6.72)$ & $6-36$ & $85(100 \%)$ & .783 \\
\hline Chance subscale & $20.22(7.24)$ & $6-36$ & $85(100 \%)$ & .788 \\
\hline Doctors subscale & $10.88(3.92)$ & $3-18$ & $85(100 \%)$ & .696 \\
\hline Others subscale & $10.87(4.13)$ & $3-18$ & $85(100 \%)$ & .764 \\
\hline Rosenberg Self-Esteem Scale & $15.73(5.97)$ & $2-28$ & $85(100 \%)$ & .849 \\
\hline \multicolumn{5}{|l|}{$(\mathrm{RSES})^{*}$} \\
\hline \multicolumn{5}{|l|}{$\underline{\text { Self Efficacy }}$} \\
\hline Total & $65.96(30.83)$ & $13-130$ & $85(100 \%)$ & .953 \\
\hline Low (13-59) & & & $41(48.2 \%)$ & \\
\hline Moderate $(60-114)$ & & & $41(48.2 \%)$ & \\
\hline High $(115-130)$ & & & $3(3.5 \%)$ & \\
\hline$\underline{\text { Stigma* }}^{*}$ & $65.50(20.80)$ & $24-120$ & $85(100 \%)$ & .953 \\
\hline \multicolumn{5}{|l|}{ Hospital Anxiety and Depression Scale } \\
\hline (HADS):Anxiety & & & & \\
\hline Total & $10.64(4.72)$ & $2-21$ & $85(100 \%)$ & .812 \\
\hline Normal $(0-7)$ & & & $25(29.4 \%)$ & \\
\hline Mild $(8-10)$ & & & $17(20 \%)$ & \\
\hline Moderate $(11-14)$ & & & $25(29.4 \%)$ & \\
\hline Severe $(15-21)$ & & & $18(21.2 \%)$ & \\
\hline
\end{tabular}

HADS: Depression 
Total

$9.24(4.92)$

$0-21$

Normal $(0-7)$

$31(36.5 \%)$

Mild (8-10)

$25(29.4 \%)$

Moderate $(11-14)$

$12(14.1 \%)$

Severe $(15-21)$

$17(20 \%)$

Note. All data in this table was calculated using pooled scores, following multiple

imputation of missing data items. * indicates measures where valid cut-off scores for categorisation within a TBI population are not provided by the scale authors or subsequent published research. 
1

2

3

4

5

6

7

8

9

10

11

12

13

14

15

16

17

18

19

20

21

22

23

24

25

26

27

28

29

30

31

32

33

34

35

36

37

38

39

40

41

42

43

44

45

46

47

48

49

50

51

52

53

54

55

56

57

58

59

60

Table 3.

Correlation matrix for pooled demographic data following multiple imputation

\begin{tabular}{|c|c|c|c|c|c|c|c|c|}
\hline & SPIN & Age & Gender & $\begin{array}{l}\text { Time since } \\
\text { TBI }\end{array}$ & $\begin{array}{l}\text { Time in } \\
\text { hospital }\end{array}$ & Employed & $\begin{array}{l}\text { Live } \\
\text { alone }\end{array}$ & $\begin{array}{l}\text { In a } \\
\text { relationship }\end{array}$ \\
\hline SPIN & 1 & & & & & & & \\
\hline Age & -.082 & 1 & & & & & & \\
\hline Gender & .207 & $-.241^{*}$ & 1 & & & & & \\
\hline Time since & .153 & $.274^{*}$ & -.207 & 1 & & & & \\
\hline TBI & & & & & & & & \\
\hline $\begin{array}{l}\text { Time in } \\
\text { hospital }\end{array}$ & .037 & .067 & -.178 & $.482^{* *}$ & 1 & & & \\
\hline Employed & $.239 *$ & .040 & $-.232 *$ & .164 & .125 & 1 & & \\
\hline Live alone & -.090 & $-.308^{* *}$ & .002 & -.175 & -.120 & -.167 & 1 & \\
\hline $\begin{array}{l}\text { In a } \\
\text { relationship }\end{array}$ & .065 & -.008 & -.172 & .121 & $.276^{*}$ & $.398 * *$ & $-.470 * *$ & 1 \\
\hline
\end{tabular}

URL: http://mc.manuscriptcentral.com/pnrh Email: Duncan.nicholas@psypress.co.uk 
Table 4.

Correlation matrix for pooled questionnaire data following multiple imputation

\begin{tabular}{|c|c|c|c|c|c|c|c|c|c|c|c|}
\hline & SPIN & $\begin{array}{l}\text { Applied } \\
\text { cognition }\end{array}$ & $\begin{array}{l}\text { MHLoC } \\
\text { Internal }\end{array}$ & $\begin{array}{l}\text { MHLoC } \\
\text { Chance }\end{array}$ & $\begin{array}{l}\text { MHLoC } \\
\text { Doctors }\end{array}$ & $\begin{array}{l}\text { MHLoC } \\
\text { Other }\end{array}$ & RSES & $\begin{array}{l}\text { Self } \\
\text { Efficacy }\end{array}$ & Stigma & $\begin{array}{l}\text { HADS } \\
\text { Anxiety }\end{array}$ & $\begin{array}{l}\text { HADS } \\
\text { Depression }\end{array}$ \\
\hline SPIN & 1 & & & & & & & & & & \\
\hline $\begin{array}{l}\text { Applied } \\
\text { cognition }\end{array}$ & $.476^{* *}$ & 1 & & & & & & & & & \\
\hline MHLoC & $.248 *$ &.- .018 & 1 & & & & & & & & \\
\hline Internal & & & & & & & & & & & \\
\hline MHLoC & $.217 *$ & .025 & $.324 * *$ & 1 & & & & & & & \\
\hline Chance & & & & & & & & & & & \\
\hline MHLoC & .033 & -.083 & .185 & .167 & 1 & & & & & & \\
\hline Doctors & & & & & & & & & & & \\
\hline MHLoC & .035 & .073 & .026 & .151 & $.379 * *$ & 1 & & & & & \\
\hline Other & & & & & & & & & & & \\
\hline RSES & $-.441 * *$ & $-.345^{* *}$ & -.013 & -.085 & .101 & -.012 & 1 & & & & \\
\hline Self & $-.472 * *$ & $-.398 * *$ & .022 & -.087 & $.237^{*}$ & $.222 *$ & $.611 * *$ & 1 & & & \\
\hline Efficacy & & & & & & & & & & & \\
\hline Stigma & $654 * *$ & $.568 * *$ & $.245^{*}$ & .207 & -.104 & .079 & $-.481 * *$ & $-.523^{* *}$ & 1 & & \\
\hline $\begin{array}{l}\text { HADS } \\
\text { anxiety }\end{array}$ & $.726^{* *}$ & $.384 * *$ & .199 & .088 & -.018 & $-.110^{*}$ & $-.492 * *$ & $-.562 * *$ & $.614^{* *}$ & 1 & \\
\hline $\begin{array}{l}\text { HADS } \\
\text { depression }\end{array}$ & $.516^{* *}$ & $.433 * *$ & -.027 & .174 & -.170 & .040 & $-.550 * *$ & $-.677 * *$ & $.582 * *$ & $.505^{* *}$ & 1 \\
\hline
\end{tabular}

